\author{
LABOUR Force PARTICIPATION AND \\ Marital Fertility of Italian Women: \\ The Role of Education
}

Massimiliano Bratti

QUADERNI DI RICERCA n. 154

September 2001 


\title{
Labour Force Participation and Marital Fertility of Italian Women: The Role of E ducation
}

\author{
MASSIMILIANO BRATTI \\ Department of Economics, Univessity of Warnidk (UK) \\ and \\ Dipartimentodi Economia, Univesità degji Studi di Amona(Italy) \\ e-mail: massib@dea.unian.it \\ First version: September 2001 \\ This version: March 2002 \\ (under revision, please do not quote)
}

\begin{abstract}
This paper uses data from the 1993 Survey of Household Income and Wealth of the Bank of Italy in order to estimate a reduced form punist model of female marital fertility and labour force participation. In particular, we focus our attention on the effect of formal education on both fertility and labour force participation behaviour, and account for the potential endogeneity of education. O ur estimates show that increasing education exerts cteisparibus (i.e. for the same age at marriage and marriage duration) a positive effect on marital fertility and that highly educated women postpone fertility and have a higher labour market attachment.
\end{abstract}

JEL:J13J22

Keywards education, fertility, Italy, labour force participation, women 


\section{Adknoukeedgements}

I wish to thank participants at the 15th Annual Conference of the European Sodidy for Population Economics (E SPE 2001, A thens), at the 16th Italian Conference of Labour Economics (AIE L 2001, Florence), especially my discussant Emilia D el Bono, and Luca Mancini and Jeremy Smith for useful comments. The usual disclaimer applies.

The Bank of Italy is gratefully acknowledged as the original depository of the Survey of Household Income and Wealth data used in this paper.

Funding from the Italian Ministry of University and Scientific Research (MURST) Project "Too many or too few? The relationship between population dynamics and socio-economic development" is also gratefully acknowledged. The author wishes to thank the Italian National Council of Economy and Labour (CNEL) for the ready delivery of the draft of the volume CNEL (2000). 


\section{Introduction}

O ne 'stylised fact' commonly observed in the developed countries is the pattern of the correlation between women's education, labour force participation (LFP hereafter) and fertility. Table 1 shows the secular trend of the average years of education in the female population, the female LFP rate and the Total Fertility Rates (TFRs) in some European countries.

Aggregated time-series data from individual countries seem to show the existence of a negative relationship between education and fertility and a positive relationship between education and LFP. However, when comparing different countries the pattern of negative correlation between education and fertility is no longer clear. Some countries with low average years of education in the female population in 1995, for example, such as Spain (6.68), Italy (6.98) and Portugal (5.22) also have very low TFRs (respectively $1.19,1.17$ and 1.49), whilst countries with higher average years of education have relatively higher TFRs, such as Finland or Norway (where average years of education and TFRs are 9.50 and 1.81, 11.41 and 1.87 in 1995, respectively).

Economists have made an attempt to explain these associations using economic models of human capital investment, fertility and labour supply. ${ }^{1}$ These models, then, have been frequently tested using aggregated time series-cross country data. ${ }^{2}$ However, such data are not ideal to testing the implications of economic models of female fertility and LFP, due to problems of aggregation and the different institutional framework characterising different countries (such as child care and contraception availability and costs, which are difficult to control for) as well as the same country over time.

\section{[Table 1 about here]}

In particular, the relationship between education and fertility is a complex one and the total effect of education may act through several pathways. Figure 1 shows that education may influence fertility both indirectly by affecting the age at marriage, and other aspects of the marriage such as duration, ${ }^{3}$ and directly, through its effect on marital fertility. Moreover, marital fertility may affect marriage duration while the expectation of family dissolution may influence fertility, LFP and the investment in human capital. ${ }^{4}$ Furthermore, education could be in part endogenous: strong preferences for market work may push women to invest more in education and perhaps to have a lower fertility (these effects operating through preferences are shown in the figure by dotted arrows). In macroeconomic studies of female fertility and LFP is difficult to isolate the different effects of education on marriage formation and dissolution, marriage duration and marital fertility. Hence, the estimated effect is a total effect that does not shed light on the mechanisms through which education affects both fertility and LFP.

[Figure 1 about here]

\footnotetext{
${ }^{1}$ See the literature on the eanomictheary of fetility, e.g. Becker (1981) and Cigno (1991).

2 For some recent examples see Cigno and Rosati (1996) and A hn and Mira (1999).

3 Smith (1997), for example, finds that rising earnings of women, which are partly due to increasing educational levels, are a significant determinant of the rising incidence of divorce in $\mathrm{G}$ reat Britain.

${ }^{4}$ Lillard and White (1999), for instance, test the hypothesis that the risk of marital disruption affects marital fertility and that marital dissolution is affected by the presence of children in the family while Parkman (1992, p. 672) maintains that 'the increase of married women labour force participation under unilateral divorce is due to the lack of compensation at divorce for reduced human capital based on sacrificed opportunities to acquire and maintain market skills'.
} 
For this reason in the present paper we focus on the investigation of married women's LFP and fertility decisions using household survey micro-data, i.e. we analyse the interactions shown by bold arrows in figure 1. In particular, we are interested in Italy, a country which has recently drawn the attention of economists and policy makers and stimulated a lively debate (see CNEL 2000) due to its exceptionally low levels of both fertility and female LFP. The study of female LFP and fertility is important for several reasons:

1. the decline in TFRs has already caused, and will exacerbate in the future, a problem of shortage of workers in Italy. In this respect, policies which aim to raise women's $\mathrm{LFP}^{5}$ can provide an effective way of attenuating the problem.

2. Another way to face the problem is to investigate the reasons of the low fertility of Italian women. Can the low fertility be considered as the consequence of a change in women's preferences or as a rational response to economic incentives? In the latter case, policy makers can influence fertility behaviour by affecting costs and incentives connected to childbearing. ${ }^{6}$

3. To analyse the impact of a widespread phenomenon, namely the increase in women's level of education, on LFP and marital fertility. This is interesting both from a positive point of view, in order to predict the possible impact of rising educational levels on female marital fertility and LFP, and from a normative point of view, since the Italian educational system has been recently targeted by an extensive reform, which, among other things, has increased the duration of compulsory schooling.

The outline of the paper is as follows. In the following section we review some of the insights into the effect of education offered by dynamic models of fertility and LFP. Section three shortly summarises the findings of the previous empirical work relating to Italy. Section four describes the data and the variables used in the empirical analysis, the econometric model and the main results. Section five concludes.

\section{Education, labour force participation and marital fertility, insights from life- cycle models}

Models of LFP and fertility can be divided into lifetime static modds and lifegde dynamic modds The former are mainly concerned with the study of completed fertility while the latter allow the analysis of a greater number of issues, such as the timing and spacing of births. In the present section we illustrate the insights into the role of education offered by some theoretic lifegde dynamic modds of fertility and LFP, since we are interested in both completed fertility and fertility tempa ${ }^{7}$

In a recent survey of theoretical and empirical work on the optimal age at motherhood Gustafsson (2001) describes in detail three theoretic models: Happel et al. (1984) , Cigno (1991) and Walker (1995). We focus here on the predictions of these models about the effect of education, while the interested reader can find their detailed description either in Gustaffson (2001) or in the original articles.

Happel et al. (1984) emphasise consumption smothingas the main determinant of fertility timing. In their model individual utility is separable into consumption and the 'effective'

\footnotetext{
${ }^{5} \mathrm{~T}$ hroughout the paper we sometimes refer to 'labour force participation' simply as 'participation'.

${ }^{6}$ In this regard, Colombino and Di Tommaso (1996) find that cohort effects, related to changes in preferences, are not significant in their analysis of fertility and LFP using Italian data for the years 1987, 1989 and 1991.

${ }^{7}$ I.e. the distribution of births over the life-cycle. In particular, we consider the fertility tempo as the average time between first marriage and births.
} 
number of children (a combination of quantity and quality of offspring). Under the perfectly imperfect capital market (PICM) assumption, i.e. individuals can not borrow against their future incomes, the husband's (exogenous) earnings profile matters for fertility timing since women give birth in a time interval in which the income of the primary earner is relatively high. According to the model wife's earnings depend on premarital work experience and when she gives birth she retires from the labour market for a fixed exogenous number of periods, during which job skills are subject to depreciation or obsolescence. Happel et al. (1984) do not consider explicitly formal education, however its effect can be roughly assimilated to that of a higher stock of pre-marital work experience (i.e. human capital), which increases the probability of a delayed first birth. The reason is that when pre-marital work experience is high the probability of total skill loss during child rearing is less, and this is the sole case in which an early birth is preferred to a late birth in the model.

Cigno (1991) and Walker (1995), instead, emphasise the carer planningmotiveas the main determinant of LFP and fertility behaviour.

In Cigno (1991) parents derive utility from consumption and 'effective' children. Parents have a positive discount rate and capital markets are perfect. In the model a higher stock of pre-marital human capital determines a lower completed fertility and early child births. This is due to the income effect, because parents discount the utility derived from offspring. As Gustafsson (2001) observes, this prediction is at odds with Happel et al. (1984) result. The differences are due to the fact that in the latter model there was a positive rate of depreciation of human capital (and women better endowed with human capital were less at risk of losing their job skills) and that no discounting was assumed. However, Cigno (1991) also maintains that women with a steeper earnings profile have a slower fertility tempo, i.e. they postpone child births. Cigno and Ermisch (1989), for instance, find that women in semi-skilled or manual occupations (who have a relatively flat earnings profile) have earlier child births than women in more skilled clerical occupations. Of course, the probability to enter skilled occupations depends, among other things, on women's education. The reason for this effect is that a withdrawal from the labour market has a current opportunity cost, the wage, and a future opportunity cost, the capital loss due to the potential job experience foregone. For a steep earnings profile the current cost is relatively lower when a woman is young while the future cost decreases with age (since there are less years of work activity left). Furthermore, the age pattern of the total opportunity cost will depend on the shape of the earnings profile. Gustafsson (2001, p. 241), for instance, observes that if it is concave the capital loss due to a later birth is very much smaller than that due to an early child birth. To summarise, in the model of Cigno (1991) education may have a two-fold effect. If education raises only the size of life-cycle wealth but does not alter the earnings profile, highly educated women are likely to give birth early in the marriage while if education alters only the earnings profile but not life-cycle wealth, namely makes it steeper, women have an incentive to postpone fertility. Finally, if education changes both the size of life-cycle wealth and the earnings profile the sign of the net effect on fertility timing can not be predicted theoretically and must be addressed empirically.

Walker (1995) specifies a dynamic model in which parents derive utility from children and consumption, have intertemporally and contemporaneously strongly separable preferences and capital markets are perfect. In Walker's model parents have a strong motive for giving births early in the life-cycle since children give a recursive flow of utility also for all periods following the birth event, which is discounted at a positive rate of time preference (unlike in Happel et al. 1984). The author does not consider in his model the effect of pre-marital human capital, however he does consider the effect of different wage profiles and maintains that changes which make the profile steeper reduce the tempo of fertility (with the same level of completed fertility) while changes which flatten the earnings profile tend to delay fertility. The reason is that during a period of increasing 
wages, cteris paribus women have an incentive to give birth early in the life-cycle, when the opportunity cost of their time is relatively less. The difference of results with respect to Cigno (1991) is due to the recursive structure of the utility of fertility and to the different specification of the wage function, which is not linear but convex in work experience. This means that the current wage foregone by giving birth and caring for children is much lower when an individual is relatively younger. In the model an increase in wealth tends by the cumulative nature of the utility flows to reduce the tempoof fertility too. Therefore, since highly educated women generally experience both a higher life-cycle wealth and a steeper wage profile (see Murphy and Welch 1992) the prediction of the model is that an increase in women's education pushes them to give birth sooner.

Blackburn et al. (1993) study the interactions between fertility timing, wages and human capital accumulation. The authors consider a dynamic model in which women make their human capital investment decision conditional on their preferences over the timing of their first birth. The model shows that if the discount rate is greater than the economy growth rate of wages for workers who do not invest in human capital, then individuals who prefer an early child birth are more likely to invest in human capital. This model, therefore, reverses the direction of the causality, which runs now from preferences over fertility timing towards women's education, suggesting the possibility of a potential endogeneity problem for women's education, neglected by the previous models.

In conclusion, different theoretic models stress different factors and motives as the main determinants of LFP and fertility behaviour and sometimes give opposite predictions about the effect of education, which rely heavily on the assumption made. Then, the question of the effect of education on LFP, fertility quantumand fertility tempo must be addressed empirically.

\section{Fertility and labour force participation in Italy: previous research}

Although there exist many studies investigating female labour supply and labour market participation conditioning on 'child services' variables and studies analysing female fertility conditioning on $\mathrm{LFP}^{8}{ }^{8}$ we review here only recent empirical work using an approach similar to ours, i.e. which jointly models and estimates female LFP and marital fertility behaviour in Italy.

Some recent contributions are:

[Table 2 about here]

Colombino and Di Tommaso (1996), who estimate a simultaneous model of female marital fertility and LFP using a sequence of cross-sections of micro data (Survey of Household Income and Wealth - SHIW - for the years 1987, 1989 and 1991). Their sample includes women aged between 18 and 40. They find that cohort effects are not significant whereas wage effects are strong and significant. They use a bivariate probit model, which though allowing for correlation between fertility and participation decisions, theoretically implies separability of the lifetime utility function into fertility and leisure, as shown by Weeks and Orme (1999). Colombino and Di Tommaso consider the effect of various measures of unearned income and wealth to investigate income effects. The effect of the regressors included is reported in table 2. Education has a positive impact on women's wage and therefore, indirectly, a positive effect on participation and a negative effect on fertility. Colombino and Di Tommaso do not account for the potential endogeneity of education.

8 For some surveys see Browning (1992), Nakamura and Nakamura (1992) and Hotz et al. (1997). 
Di Tommaso (1999), who estimates a trivariate model of women's participation, fertility and wages using SHIW data for the same period as Colombino and Di Tommaso (1996). She uses a sample of women aged 18-40. Results are shown in table 2. Schooling has a positive impact on participation and a negative impact on fertility through the effect on wages. From the technical point of view the econometric specification of Di Tommaso is based on the restrictive assumption of separability of the lifetime utility function into leisure and fertility. Education is considered exogenous.

De Boca (1999), who analyses the role of market rigidities upon participation and fertility behaviour of Italian married women. She performs cross-section and panel data analyses using data from the SHIW for the years 1991, 1993 and 1995. Her sample includes women aged 21-45. The preferred model is the fixed effects model, which does not allow the estimation of the effect of education. Results are shown in table 2. In the crosssections education has a positive impact on fertility for the 1991 and 1995 cohorts and a positive impact on participation for all three years. From a technical point of view her panel estimation procedure rests upon the assumption of independence of fertility and LFP decisions. In that case, once eliminated the unobserved heterogeneity using a fixed effects model, the two logit models for participation and fertility can be estimated separately. However, for the estimation of the cross-sections she uses separate logit models without accounting for the possible correlation between the two decisions (unlike Colombino and Di Tommaso 1996). This study does not account for the possible endogeneity of education.

With respect to the previous studies:

1. we use 1993 SHIW data. The choice of the cohort depends on the availability of the variables that are used in the econometric specification (in particular data on child care availability by province of residence). ${ }^{9}$

2. we consider a flow-fertility variable (a precise definition is given in section 4.3) and by including some interaction terms between years of education and age, we analyse also issues related to the effect of education on fertility timing. ${ }^{10}$

3. we explicitly consider family background variables that could affect a woman's, or her husband's, preferences towards fertility and LFP, often neglected in past empirical work.

4. we use a multinomial model. A multinomial model is more general than a bivariate model since it accounts for the possible non-separability of the life-cycle utility function into leisure and fertility, as shown in Weeks and Orme (1999). Di Tommaso and Weeks (2000), for instance, in an application of Weeks and Orme (1999) to LFP and fertility decisions on UK data find that the bivariate probit and logit models, which imply a restrictive form of additive separability across the decisions, are rejected in favour of their multinomial counterparts.

5. we estimate a reduced form-punist model, in the language of Browning (1992). In particular we are interested in the effect of education upon fertility and LFP. Therefore, in the empirical specification we do not include 'child services' variables,

\footnotetext{
${ }^{9}$ D el Boca (1999) uses data on child care availability at the regional level.

10 Due to the cross-sectional nature of our study, in principle it could not be possible to distinguish between age and cohort effects. This problem is overcome by including in the empirical work some proxies for the individual preferences towards 'taste for market work', which proxy for cohort effects or secular trends. Accordingly, we interpret the effect of the interaction terms between education and age as the impact of education on the timing of fertility and LFP.
} 
which are endogenous, but only their determinants, such as a woman's level of education. $^{11}$

6. we account for the potential endogeneity of female education, firstly by including several possible controls for the 'taste for market work' and then by applying a Non Linear Instrumental V ariables (NLIV) estimation strategy.

\section{The empirical analysis}

In the following sub-sections we describe the methodology and the results of the empirical analysis.

\subsection{The econometric model}

In this section we describe the underlying behavioural model and the reduced form multinomial logit model estimated using Italian data.

Let us consider a woman who maximises her life-cycle utility defined as:

$U=U_{P M}+U_{M}$

where $\mathrm{U}_{\mathrm{PM}}$ and $\mathrm{U}_{\mathrm{M}}$ are pre-marital and marital utility, respectively:

$U_{P M}=\sum_{0}^{t_{M}} \beta^{t} u\left(c_{t}, B_{t}, s_{t}\right)$

$U_{M}=\sum_{t_{M}}^{T} \boldsymbol{\beta}^{t} u\left(c_{t}, B_{t}, s_{t}\right)$

and $t_{M}$ is age at marriage, ${ }^{12} T$ is the length of the planning horizon, $\beta$ is the discount factor, $\mathrm{u}($.$) sub-period felicity functions, \mathrm{c}$ consumption, $\mathrm{B}_{\mathrm{t}}$ a child birth (which can assume value 0 or 1 ) and sq spare time, all in period t. A woman is subject to $T+1$ subperiod budget constraints:

$c_{t}=A_{t}+w_{t} l_{t}-p_{c} B_{t} t_{c t}$ for $\mathrm{t}=0, \ldots, \mathrm{T}$

where $A_{t}$ is exogenous non-labour income (e.g. parents' income during the pre-marial period and husband's income during marriage), wt the wage rate, $l_{t}$ labour supply, $p_{t}$ the price of one unit of market child care and the time of child care purchased in the market, all in period t. We have assumed perfectly imperfect capital markets (PICM); ${ }^{13}$ and $\mathrm{T}+1$ time constraints:

$1=l_{t}+s_{t}+h_{t}+B_{t} m_{t} \quad$ for $\mathrm{t}=0, \ldots, \mathrm{T}$

11 This means, for instance, that the probability that a woman gives birth in a specific year depends on her desired level of completed fertility and fertility timing (hence on her realised fertility), whose effects are picked up in the empirical specification by their 'first determinants', such as her level of education.

12 For the sake of brevity here we assume that women do not plan more than one marriage or to get divorced and that they are feundablefor the whole life-cycle (alternatively $\mathrm{T}$ can be considered as the end of the fecund time-span and the life-cycle utility will include a third term for the utility of the non-fecund period).

13 See Hotz et al. (1997). 
where $\mathrm{m}$ is mother's time devoted to child care ${ }^{14}$ and $\mathrm{h}$ the time devoted to formal education both in period t The total time endowment is normalised to one.

Moreover, the wage can be considered as an increasing function of both the stocks of job market experience $\left(\mathrm{J}_{t}\right)$ and of formal education $\left(\mathrm{H}_{t}\right)$, i.e. $w_{t}=f\left(J_{t}, H_{t}\right)$, where $J_{t}=\sum_{0}^{t-1} l_{t}$ and $H_{t}=\sum_{0}^{t-1} h_{t}$.

Under standard regularity conditions this problem can be solved giving an optimal lifecycle plan for the choice variables $\mathrm{c}_{\mathrm{t}} \mathrm{B}_{\mathrm{t}} \mathrm{s}_{\mathrm{t}} \mathrm{h} \mathrm{m}_{\mathrm{t}} \mathrm{t}_{t}$ and $\mathrm{t}_{\mathrm{M}}$.

We code participation in period tas $\mathrm{L}_{\mathrm{t}}=1$ (i.e. $\mathrm{l}_{\mathrm{t}}>0$ ), non-participation as $\mathrm{L}_{\mathrm{t}}=0$, the decision to give birth in period t as $\mathrm{B}=1$ and the decision not to give birth as $\mathrm{B}=0$ and focus here our attention only on marital utility. Therefore, we assume that women have already made their maximising choices in their pre-marital period and we condition on those optimal choices.

Focusing on $\mathrm{L}_{\mathrm{t}}$ and $\mathrm{B}_{\mathrm{t}}$ only and omitting in the notation the other choice variables, the optimal life-cycle plan concerning LFP and fertility can be stated as:

$\mathrm{P}^{*}=\left\{\left(\mathrm{L}_{1}^{*}, \mathrm{~B}_{1}^{*}\right),\left(\mathrm{L}_{2}^{*}, \mathrm{~B}_{2}^{*}\right), \ldots,\left(\mathrm{L}_{\mathrm{T}}^{*}, \mathrm{~B}_{\mathrm{T}}^{*}\right)\right\}$

In period the probability to observe $\mathrm{L}_{\mathrm{t}}=\mathrm{z}$ and $\mathrm{B}=\mathrm{j}$, where $\mathrm{z} \mathrm{j}=\{0,1\}$ is the probability that the couple of decisions $\left(\mathrm{L}_{\mathrm{t}}=\mathrm{z}, \mathrm{B}=\mathrm{j}\right)$ is included in the optimal life-cycle plan, i.e. $\operatorname{Pr}\left[\left(\mathrm{L}_{\mathrm{t}}=\mathrm{Z}, \mathrm{B}_{\mathrm{t}}=\mathrm{j}\right) \in \mathrm{P}^{*}\right]$. If we define as $\mathrm{V}_{\mathrm{t}}$ the life-cycle utility function evaluated at time $\mathrm{t}$ this probability can be expressed as:

$$
\begin{array}{r}
\operatorname{Pr}\left[\mathrm{V}_{\mathrm{t}}\left\{\left(\mathrm{L}_{1}^{*}, \mathrm{~B}_{1}^{*}\right),\left(\mathrm{L}_{2}^{*} \mathrm{~B}_{2}^{*}\right), \ldots,\left(\mathrm{L}_{\mathrm{t}}=\mathrm{Z}, \mathrm{B}=\mathrm{j}\right), \ldots,\left(\mathrm{L}_{\mathrm{T}}^{*}, \mathrm{~B}_{\mathrm{T}}^{*}\right)\right\}\right. \\
\left.\mathrm{V}_{\mathrm{t}}\left\{\left(\mathrm{L}_{1}^{*}, \mathrm{~B}_{1}^{*}\right),\left(\mathrm{L}_{2}^{*}, \mathrm{~B}_{2}^{*}\right), \ldots,\left(\mathrm{L}_{\mathrm{t}}=\mathrm{h}, \mathrm{B}=\mathrm{B}\right), \ldots,\left(\mathrm{L}_{\mathrm{T}}^{*}, \mathrm{~B}_{\mathrm{T}}^{*}\right)\right\}\right]
\end{array}
$$

$\forall(\mathrm{h}, \mathrm{k}) \neq(\mathrm{z}, \mathrm{j})$. The four different outcomes for $\left(\mathrm{L}_{t}, \mathrm{~B}\right)$ can be recoded to obtain a single dependent outcome variable $Y_{i t}$, where the subscript i refers to the individual:

$$
Y_{i t}=\left\{\begin{array}{l}
1 \text { if } L_{\mathrm{it}}=0, B_{i t}=0(\mathrm{NP}, \mathrm{NF}) \\
2 \text { if } L_{\mathrm{it}}=1, B_{i t}=0(\mathrm{P}, \mathrm{NF}) \\
3 \text { if } L_{\mathrm{it}}=0, B_{i t}=1(\mathrm{NP}, \mathrm{F}) \\
4 \text { if } L_{\mathrm{it}}=1, B_{i t}=1(\mathrm{P}, \mathrm{F})
\end{array}\right.
$$

$(\mathrm{NP}, \mathrm{NF})$ stands for 'non participation-non fertility', (P,NF) for 'participation-non fertility', (NP,F) for 'non participation-fertility' and (P,F) for 'participation-fertility'.

Now we can define the life-cycle expected utility function as $\mathrm{V}_{\text {yit }}$, where tis the current period (that we are observing) and yis one of the four possible outcomes of $Y_{\text {it }}$ for the individual i. Adopting a linear specification we have:

$$
V_{y i t}=X_{i t}{ }^{\prime} \beta_{y}+\varepsilon_{y i t}
$$

where $\mathrm{X}_{\mathrm{it}}$ is a vector of exogenous explanatory variables and $\varepsilon_{\mathrm{yit}}$ is a random variable unobservable to the econometrician (e.g. differences in tastes). By assuming a Type I extreme-value distribution for $\varepsilon_{\mathrm{jit}}$ and independence across the $\varepsilon_{\mathrm{y}}^{\prime}$ s, the multinomial logit

\footnotetext{
14 The reason why we consider a traditional modd of family (see Del Boca 1997), in which women are the primary responsible for child care and the behaviour of the husband is considered exogenous, are given in section 4.2 .
} 
model (MNL) can be derived from utility maximisation (result originally due to McFadden 1974). In this case the probability of observing $Y_{\mathrm{it}}=1$, for instance, is:

$$
\operatorname{Pr}\left[Y_{i t}=1\right]=\operatorname{Pr}\left[V_{1 i t}=\underset{y}{\arg \max } V_{y i t}\right]=\frac{\exp \left(X_{i t}{ }^{\prime} \boldsymbol{\beta}_{1}\right)}{\sum_{y=1}^{4} \exp \left(X_{i t}{ }^{\prime} \boldsymbol{\beta}_{y}\right)}
$$

As equation (7) shows the value of life-cycle utility at time tis a function of past, current and future choice variables. In the empirical specification we should include among the regressors only exogenous variables if we want to estimate unconditional effects (such as in the puristapproach described in Browining 1992).

Moreover, our framework shows that when studying empirically married women's LFP and fertility behaviour education can not be considered as an exogenous variable. In fact, it is likely that the form of a woman's preferences, i.e. the relative weight in which consumption, offspring and leisure enter her utility, affects her optimal human capital investment. ${ }^{15}$

\subsection{Some possible determinants of female labour force participation and fertility}

In the empirical model we include the exogenous or predetermined variables that, acting through preferences or the budget constraint, affect women's marital fertility and LFP. The relevant factors are well summarised in Lehrer and Nerlove (1986) and Dex and Joshi (1999). Here we consider.

The role of the partner. The husband ${ }^{16}$ may affect in several ways a woman's fertility and participation decisions. If we adopt a unitary model of family, LFP decisions are jointly made by the spouses, as are fertility decisions. This suggests that husband's labour incomes $\left(\mathrm{A}_{\mathrm{t}}\right.$ during the marriage in the model) are endogenous in that setting (in the sense that they are jointly determined with female labour supply). If we adopt a collective model of family (see Chiappori 1992) labour force and fertility decisions are individually made by each spouse who takes into account her/ his non-labour incomes and the income of her/ his partner (since family incomes are shared according to a certain 'sharing rule'). Unfortunately, in this case past non-labour incomes depend on past LFP, fertility and saving behaviour and are likely to be endogenous. We think that because of the strong institutional rigidities existing in the Italian labour market (see D el Boca 1999) where part-time jobs are scarce ${ }^{17}$ and women have a primary responsibility in child rearing, the hypothesis that family labour supply is jointly determined by the spouses is not adequate: Italian men generally work and have limited degrees of freedom about the number of hours worked so that their incomes can be considered as exogenous with respect to female labour supply and fertility decisions. Therefore, a traditional family mode (see D el Boca 1997) is probably more suitable to the Italian case: ${ }^{18}$ a woman makes her participation and fertility decisions taking into account the fact that she can share with

\footnotetext{
15 There is also a literature (see for instance Parkman 1992, 1997) showing that women may increase their level of formal education and LFP as a form of insurance against the risk of separation and divorce. In this case the optimal levels of education and LFP depend also on the characteristics of the marriage.

16 Hereafter, we use the nouns spouse, husband and partner exchangeably.

17 As discussed in Del Boca (1999) the lack of part-time jobs may be endogenous if determined on the supply side. In this regard using SHIW 1989 data Giannelli (1996) finds that about 13\% of employed women work longer hours than they wish, while using data from Tuscany the figure is $34.8 \%$.

18 D el Boca (1997, p. 76) finds that the traditional familymodd can not be rejected using SHIW 1993 data.
} 
her partner some family resources (and therefore also her partner's incomes). The sign of the impact of husband's income on female fertility can not be determined theoretically. In models that only account for the quantity of children the expected effect is positive. In contrast, in models accounting also for the demand for quality the effect is generally expected to be negative (see De Tray 1973 and Becker and Lewis 1973). Then the question must be addressed empirically.

Besides the role of husband's income, we consider other husband-related variables that may affect a woman's LFP and fertility decisions, namely job qualification, branch of activity, education and age. The first three variables are proxies for the husband's permanent income and income profile (i.e. $\sum_{t_{M}}^{T} A_{t}$ and the sequence of $A_{t}$ ) while the fourth is a proxy for a woman's probability of conception. Moreover, the last two variables may also affect the husband's attitude towards his wife LFP.

Preferences and ailtural factors. We consider the effect of the gender rde modd that a woman inherited from her mother and the attitude of the husband towards his wife LFP. Namely, we include among the explanatory variables the job qualification and branch of activity of a woman's mother and the fact that her mother in law worked (in the model this effect runs through the form of sub-period felicity functions). ${ }^{19}$

Childcare Women have to decide which form of child care to use and how many hours of child rearing to allocate to the market. For this reason we include in the econometric specification some variables related to the availability of external child care (which in the model affects $p_{c}$, the price of external child care), in particular public and informal child care (i.e. child care provided by a woman's parents or parents in law).

Femaleeducation In this paper we focus our attention on the role of formal education $\left(\mathrm{H}_{\mathrm{t}}\right.$ in the model) in shaping participation and fertility decisions of married women. Women's stock of formal education at time $t$ is a predetermined variable. This does not exclude that it could be endogenous: women with a higher 'taste for market work' could simultaneously invest more in education, and have a higher LFP and a lower fertility. ${ }^{20}$ The observed correlation between education, LFP and fertility would be in this case only spurious and driven by a fourth factor: 'taste for market work'. For this reason we shall account in the empirical work for the possible endogeneity of education by including a wide range of family variables which control for heterogeneity in the 'taste for market work', in the spirit of the proxying and matching mohod(see Blundell et al. 1997), and by applying a Non Linear Instrumental Variables (NLIV) estimation strategy.

Eastedinmodd. Although in section 4.1 we have considered LFP and fertility decisions as the outcomes of maximising behaviour, as observed in Gustafsson (2001), for some time the main rival theory to neoclassical models of fertility was the so called Easterlin model (see for instance Macunovich 1996). For this reason we also includes some variables related to the Easterlin relativeincomehypthesis In the Easterlin model 'the driving force behind both increased LFP and reduced fertility, is the desire of a large cohort to improve relative economic status, with parental income as a measure of that cohort's material aspirations.' (Macunovich 1996 p. 95). A survey of the results of works attempting to test the Easterlin relativeincomehypthesis is reported in Macunovich (1996). They have usually employed proxies for relative incomes, such as parental occupational status, and the empirical evidence on the validity of the hypothesis is 'mixed'.

\footnotetext{
${ }^{19}$ Similar variables are used in D el Boca et al. (2000, p.49) who, for instance, find a small added worker effect (i.e. a higher probability of participation) for women whose mother or mother in law worked.

20 For a discussion of the endogeneity of education see also Macunovich (1996, pp. 118-119).
} 


\subsection{Data Description}

The data used are drawn from the 1993 Survey of Household Income and Wealth (SHIW) of the Bank of Italy. The SHIW is the most popular source of micro-data for Italy. For a detailed description the interested reader can see Banca d'Italia (1995) and Filippin (1997). The nature of the SHIW, which does not include data on fertility and LFP histories, does not allow us to estimate a complete life-cycle model. Hence, we have to rely on cross-sectional data, in particular we use 1993 data. We consider women aged between 21 and 39 cohabiting with their husband or partner, for whom we have information in the data set, and exclude from the sample self-employed women. ${ }^{21}$ The sample includes 1467 women. We choose the same age interval as Del Boca (1999), which is the study closest to ours among those listed in section 3 for the definition of fertility, but discard women in the age class 40-44. This is done since our 'economic model' of participation and fertility can explain only desired fertility, and we want to focus on ages at which women have a high feundability. ${ }^{22}$

As we have already emphasised our main focus is on the effect of formal education. Since the SHIW contains information only on the highest educational qualification obtained, we computed the number of years of education using the years of legal duration of the different educational grades, as follows: primary school (sauda demetare) 5 years; low secondary school (sauda mediainfeiioe) - 8 years; high secondary school (sauda media superia) - 13 years; tertiary education (laurea) - 17 years. ${ }^{23}$ Years of education are interacted with four age dummies (21-24, 25-29, 30-34, 35-39), which enables us to study the effect of education on the timing of fertility and LFP.

As to the dependent variables we define participation as employment or unemployment and consider as non-participating women who replied to the SHIW that they were housewives. ${ }^{24}$ We consider a birth event as the presence in the family of a child more than one and less than two years old. O ur choice depends on the fact that we want to analyse the effect of education and other variables on the decision to give birth and to participate in the labour market. For this reason we consider a flow fertility variable rather than a stock fertility variable. We consider children more than one and less than two years old since we do not know the exact age (number of months) of children less than one year old and we want to avoid considering periods when participation in the labour market is not possible, e.g. in the first months immediately after a child birth. ${ }^{25}$ Therefore, we study the issue of fertility and LFP in the period surrounding a birth event. This provides nonetheless useful information on future labour market participation. ${ }^{26}$ In the model we explicitly control for the geographic area of residence, municipality size, husband's income, parents' availability, Easterlin's variables, parents' education, parents' job qualification, parents' branch of activity, husband's education, husband's job

\footnotetext{
${ }^{21}$ Like all the articles reviewed in section 3.

22 We observe only realised fertility. Although in our economic model realised and observed fertility are equal, in the reality they may differ because of problems of infecundity and the effectiveness of contraception. Therefore, we included in the analysis only the ages at which a woman's degree of feendability is relatively high and for which an 'economic model' of fertility and participation, which explains only desired fertility, makes sense.

${ }^{23}$ We dropped individuals without formal education and those with post-graduate qualifications, whose number is very low, in order to avoid spurious results.

${ }^{24}$ Hence, we drop students.

${ }^{25}$ For the same reason we exclude from the sample women with a child aged less than one, since for them giving birth may not be possible.

26 Previous studies focusing on first birth (Mott and Shapiro 1979, 1983) showed that women who did not enter the labour market before two years since a birth event have a high probability of staying out of the labour market for the rest of their life.
} 
qualification and economic branch, husband's age, public child care availability and potential informal child care availability. The rationale for the inclusion of these variables along with their description is given in Appendix A.

When it was possible we preferred using missing-value dummies rather than discarding observations for which some variables had missing information. Unfortunately, this was not always possible. In fact, for women for whom data on father's or mother's education was missing not all the four MNL outcomes were observed, which caused major problems to the model estimation. Hence, we decided to drop observations with missing data on parents' education (47 observations, $3.2 \%$ of the sample). ${ }^{27}$ Therefore, the final sample includes 1420 women. Table 3 shows the distribution of the four MNL outcomes by level of women's education: the positive correlation between education and participation is evident, however the data show also a positive correlation between education and fertility for participating women.

[Table 3 about here]

\subsection{Econometric strategy}

In order to assess the effect of education we adopt the following empirical strategy:

1. We include in the model specification a wide range of controls for a woman's family background that may proxy for unobserved heterogeneity in the 'taste for market work' (in the spirit of theproxyandmatdingmthod, see Blundell et al. 1997);

2. We apply a Non Linear Instrumental Variables estimation strategy, by 'instrumenting' education, in order to account for its potential endogeneity.

The estimated effect of education in models of women's marital fertility and LFP may be partly spurious. It might be unobserved individual heterogeneity (e.g. unobserved preferences for market work) which pushes women to invest more in education and also affects their LFP and fertility decisions later on. ${ }^{28}$ One way of controlling for the presence of unobserved heterogeneity (which may affect our estimates) is to include a wide range of family background variables, which are likely to shape a woman's preferences, in the model..$^{29}$ We included father's and mother's education, job qualification and branch of activity, which could affect a woman's 'taste for market work'. The full set of estimates of this model are reported in table B1 in Appendix B while the coefficients of the educational variables are listed in table 4.

Since the MNL model uses the maintained assumption of the Independence of Irrelevant Alternatives (IIA), we performed some specification tests to assess the validity of this assumption (see Hausman and McFadden 1984). All tests (see table B2 in the Appendix B) concluded that the IIA could not be rejected by our data.

Clearly, even after controlling for possible taste heterogeneity women's education retains its significance. In order to obtain a 'parsimonious' model we performed some

\footnotetext{
27 The rate of non-response for other parental variables (such as parents' jobs) is of the same order of magnitude. All regressions use a weight computed by the Bank of Italy which is the inverse of the probability that an individual is included in the sample.

${ }^{28}$ In the model of Blackburn et al.. (1993), for example, it is the preference for late childbearing which pushes women to invest more in human capital.

29 These information are provided by the SHIW at the respondent's age. The same procedure is applied, for instance, by Blackburn et al. (1993).
} 
Likelihood Ratio (LR hereafter) tests for the different groups of regressors. ${ }^{30}$ The groups of regressors that were not significant at the 10\% level, when individually tested, were father's job qualification and branch of activity and husband's job qualification and branch of activity. However, when jointly tested the restrictions were not valid, while the model omitting only father's qualification and branch of activity was an admissible reduction of the general model..$^{31}$ The estimates of the 'parsimonious' model are shown in table B3 in Appendix B.

\section{[Table 4 about here]}

Although the introduction of a wide range of controls to account for unobserved heterogeneity helps to obtain consistent estimates, it does not exclude that the left-out heterogeneity may still be important. For this reason we apply a Non Linear Instrumental Variables Estimator ${ }^{32}$ (NLIV), by 'instrumenting' education. We use as identifying instruments father's job qualification and branch of activity, which the first part of the analysis suggested do not affect women's LFP and fertility, but which might affect their education. Table B4 in Appendix B shows the estimate of the education equation. The instruments turn out to be very significant in the explanation of the number of years of education achieved. Following the suggestions of Bound et al. (1995) we computed a LR test for the joint significance of the identifying instruments. The value is $\chi^{2}(8)=48.82(p-$ value: 0.00 ), which confirms that the instruments are quite good. The full set of estimates obtained using the NLIV procedure is shown in table B5 in Appendix B.

The NLIV estimator though largely used in the empirical literature has an important potential pitfall. The non-linearity of the MNL model may cause the inconsistency of the estimates even if some very good instruments (i.e. variables orthogonal to the residual of the latent linear model, $\varepsilon_{\mathrm{yt}}$ in equation (9) in our case) are used for the potentially endogenous explanatory variable. This result is proved using simulation by Dagenais (1999) and analytically in a particular case by Lucchetti (2000). The inconsistency arises from the potential correlation between the residuals of the non-linear model and the set of instruments used. In order to have a raw idea of the potential asymptotic bias of the estimates D agenais (1999) reports the correlation between the residuals of the non-linear model and the identifying instruments. We do the same using the predicted residuals from the MNL model; the correlations are shown in table B6 in Appendix B. The results are quite reassuring: all correlations are very close to zero, suggesting that the magnitude of the asymptotic bias is likely to be negligible.

However, from table 4 is clear that using the NLIV estimator greatly reduces the precision of the estimates of the coefficients of education. ${ }^{33}$

In order to test the endogeneity of education we performed the Smith and Blundell's (1986) weak exogeneity test, including the predicted residual from the education equation in our 'parsimonious' MNL model. The predicted residual included in the artificial regression turned out not to be significant $\left(\chi^{2}(3)=1.25\right.$, $p$-value $\left.=0.74\right)$. Hence, we conclude that our data does not allow to reject the null hypothesis of weak exogeneity of education with fertility and LFP. This is not an unusual result, Sander (1992), for instance, finds similar results in his study of the effect of women's schooling on fertility in the United States. For this reason we prefer to focus on the estimates of the 'parsimonious' MNL model, since the effect of education is more precisely estimated.

\footnotetext{
30 They are available upon request from the author.

${ }^{31}$ At the $5 \%$ statistical level of significance $\left(\chi^{2}(24)=33.03\right.$, $p$-value $\left.=0.10\right)$.

32 See Grogger (1990).

${ }^{33}$ However, a LR test for the joint omission of the four variables for female education was rejected at the $5 \%$ significance level $\left(\chi^{2}(12)=51.37\right.$, p-value $\left.=0.00\right)$.
} 
In the light of these results, table 5 shows the predicted probabilities of the four MNL outcomes by level of education and age group computed at the sample average of all the remaining variables using the 'parsimonious' MNL model. Since no married woman in our sample turns out to have a university degree at age 21-24 we do not simulate the LFP and fertility behaviour of women with a tertiary education for this age group and consider their probability to give birth as null.

[Table 5 about here]

\subsection{The effect of education}

It is clear that education raises the labour force attachment of women, who continue to participate in the labour market even in the period surrounding a birth event. Moreover, better educated women tend to postpone fertility.

Both for women with high secondary and tertiary education the probability of giving birth peaks at the ages $25-29$ (10.2\% and $17.8 \%$, respectively), whereas for women with low secondary and primary schooling it reaches the maximum at the ages $21-24$ (9.8\% and $6.2 \%$, respectively). Women with primary and low secondary education have very similar probabilities of giving birth at the ages 21-34. Women with a university education have remarkably higher fertility rates at the ages 30-39, especially compared to women with low secondary and primary schooling. Interpreting the sum of the probability of giving birth for the different age groups by educational level as a raw measure of the hypothetical marital fertility at ages 21-39 (24-39 for women with tertiary education), assuming that all women get married between age 21 and 24 ( between ages 25 and 29 for women with tertiary education) and that their marriage lasts at least until they are in the age interval 35-39 (this is a measure of period fertility, in particular the total fertility of an hypothetical cohort with the age-specific fertility rates observed in a certain year), it is evident that ceteis paribus i.e. for an equal duration of marriage, ${ }^{34}$ the marital fertility of highly educated women would be higher. A rising pattern of fertility with education is found by Ben-Porath (1973) and Dazinger and Neuman (1989) for Israel and Moffit (1984) for the US. Bloemen and Kalwij (2001) using data from the Netherlands find that 'an increase in years of schooling of a woman causes her to schedule births later in life but it does not significantly affect her completed fertility' (p. 593). A rising marital fertility with increasing education could be explained by the prevalence of income over substitution effects at higher levels of education, especially when child care can be purchased in the market (see for example Ermisch 1989). In that case, in fact, the opportunity cost of giving birth for a woman is the lowest between the income and experience lost by withdrawing from the labour market to care for children and the cost of external child care. Highly educated women, therefore, are more likely to work and to purchase with their incomes external child care and, given her higher expected amount of life-cycle wealth, they could eventually 'afford' also a higher fertility. Blau and Hagy (1998), for instance, find for the US a positive effect of the mother's wage rate on the probability to buy external child care and conclude that: 'paid child care arrangements and more formal arrangements are complementary to being employed' (p. 127). In contrast, Chiuri (2000) using 1993 SHIW data does not find a positive effect of education on the probability of using external child care. However, the SHIW data do not include information on use and cost of nannies and given the strong restrictions in the places and the timetable available (see D el Boca 1999), especially for the cèthes nannies might be an

34 For the women with a university degree the hypothetical marriage duration is between age 25 and 39. 
important form of external child care purchased by women working full-time with children aged under two (i.e. in our case).

It is worth noting that this is only a part of the overall effect of education on fertility, namely the effect on marital fertility at ages 21-39. But as we have seen in figure 1 education may influence also non-marital fertility and fertility before age $21{ }^{35}$ and marital formation and dissolution. What we have estimated is simply the effect of education on marital fertility for the age classes 21-39, conditional on marriage or cohabitation. ${ }^{36}$ Therefore, the fact that for married (or cohabiting) women education raises the probability of giving birth at ages 21-39 does not imply that education raises completed fertility in the whole population. However, since in Italy the nuptiality rate at ages before 21 is very $l o w^{37}$ our estimated effect can be roughly interpreted as the effect of education on marital fertility.

O ur findings are not necessarily in contrast with the evidence for the less developed countries (LDCs), which generally shows, instead, that female education has an important negative effect on fertility (see for instance Schultz 1993). Firstly, if one refers to overall (and not only marital) fertility is clear that education may negatively affect fertility by increasing the age at first marriage. Secondly, if one considers marital fertility (see, for instance, Lam and Duryea 1999) some possible explanations for these apparently opposite findings are that while in the developed countries is usually assumed that contraceptive methods are largely available and used for family planning, in poor countries, where education is very low, a rise in schooling could affect the use and the effectiveness of contraceptive methods and lead to fewer unwanted births (see Rosenzweig and Schultz 1985). Moreover, while models for developed countries usually assume an altruistic, or consumption, motive to have children (see Becker 1981), models for LDCs often stress an egoistic, or investment, motive to have children: the so-called ddageseunity hypothesis (see Cigno 1991). Therefore, the determinants of fertility may be very different in countries at different stage of development (see Hotz et al 1997 for the developed countries and Schultz 1997 for low income countries).

We find that especially for women with primary and low secondary schooling working in the labour market appears to be scarcely compatible with child rearing. In fact, most 'fertile' women do not participate in the labour market. The opposite is true for women with high secondary and tertiary education who give birth. This could be explained, as we have already said, in terms of the higher value of time and the better access to external private child care on the part of better educated women.

The probability of LFP increases monotonically with years of formal education and age. Women with tertiary education, for instance, are more than three times more likely to participate in the labour market than women with primary schooling at ages 35-39.

Apart from the exact measures of the estimated effects, we think that the qualitative suggestions of our analysis are quite clear-cut. Firstly, education raises LFP of women, especially of women giving births; secondly, for married women aged 21 to 39 the probability of giving birth increases with years of formal education; finally, education determines a fertility postponement.

The reasons for the fertility postponement could be explained by the economic models reviewed in section 2 . For highly educated women an early withdrawal from the labour market is costly both in terms of current opportunity costs (i.e. wages) and future accumulation of human capital (career planningmative). Moreover, highly educated women might decide to give birth when their current incomes are relatively higher (consumption

\footnotetext{
35 Gustafsson et al. (2001), for instance, find that in Britain, Germany, the Netherlands and Sweden combining motherhood and education is not generally chosen by women.

${ }^{36}$ As we have already noticed we do not address in this paper the potential endogeneity of the marital status.

37 In 1993 the nuptiality rate at age 20 (i.e. number of married women aged 20/ number of women aged 20), for instance, was 4.87\% (electronic data from ISTAT, Italian National Institute of Statistics).
} 
smothing motive, that usually happens at higher ages given the steeper wage profile for high skilled jobs.

\section{Concluding remarks}

In this paper we have developed an analysis of female marital fertility (at ages 21-39) and LFP decisions using data from the 1993 Survey of Household Income and Wealth of the Bank of Italy. We had a primary interest in the role of education in shaping labour market and marital fertility decisions and therefore a primary concern about its potential endogeneity. The potential endogeneity of education has been accounted for by including in the model a wide range of controls (proxyingand matchingmethod), which are proxies for heterogeneity in the 'taste for market work', and using a Non Linear Instrumental Variables (NLIV) estimation strategy. After controlling for a wide range of characteristics of a woman's family and marital background we find no evidence of endogeneity of education with labour force participation and fertility. Our main findings are the followings:

1. education raises the job attachment of women, in particular highly educated women work also in the period surrounding a birth event;

2. there is some evidence of a cteis panibus rising pattern of marital fertility with increasing education at ages 21-39, which can be explained in terms of the prevalence of income over substitution effects due to education and by the greater opportunity of access to external private child care for highly educated women;

3. rising education determines a fertility postponement, which can be explained by the career planningand the consumptionsmothingmotives.

O ur results have important policy implications. Policies which aim to increase women's education have a positive impact both upon LFP and marital fertility. In particular, we expect that the recent increase in the duration of compulsory schooling introduced in Italy will raise future female LFP. 


\section{Figures in the main text}

Figure 1. Women's Education, fertility and labour force participation: some possible interactions

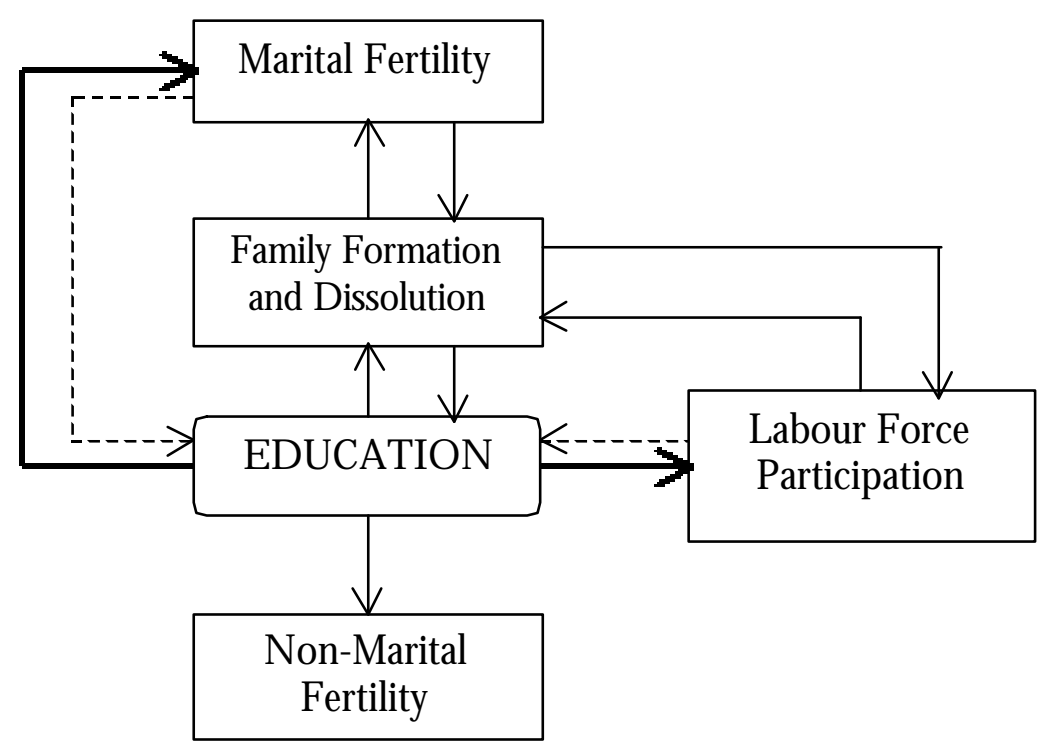

Note In the present paper we focus only on the interactions shown by bold or dotted arrows. 
Tables in the main text

Table 1. Women's years of education, TFRs and labour force participation in some European countries

\begin{tabular}{|c|c|c|c|c|c|c|c|c|}
\hline \multirow{2}{*}{ Country } & \multicolumn{8}{|c|}{ Year } \\
\hline & 1960 & 1965 & 1970 & 1975 & 1980 & 1985 & 1990 & 1995 \\
\hline \multicolumn{9}{|c|}{ A verageyears of education per woman aged muethan 14 (a) } \\
\hline Finland & 5.54 & 5.86 & 6.22 & 6.67 & 7.11 & 7.64 & 9.23 & 9.50 \\
\hline Italy & 4.38 & 4.64 & 5.11 & 5.26 & 5.43 & 5.72 & 6.09 & 6.48 \\
\hline Norway & 5.71 & 5.96 & 6.72 & 7.12 & 7.74 & 8.83 & 11.26 & 11.41 \\
\hline Portugal & 1.44 & 2.01 & 2.14 & 2.37 & 3.42 & 3.54 & 4.63 & 5.22 \\
\hline Spain & 3.75 & 3.96 & 4.39 & 4.37 & 5.47 & 5.48 & 6.28 & 6.68 \\
\hline UK & 7.86 & 7.46 & 7.83 & 8.04 & 8.25 & 8.49 & 8.74 & 9.06 \\
\hline \multicolumn{9}{|c|}{ Total FetilityRates (TFRs) (b) } \\
\hline Finland & 2.71 & 2.40 & 1.83 & 1.69 & 1.63 & 1.64 & 1.78 & 1.81 \\
\hline Italy & 2.41 & 2.66 & 2.42 & 2.21 & 1.64 & 1.39 & 1.26 & 1.17 \\
\hline Norway & 2.85 & 2.93 & 2.50 & 1.99 & 1.72 & 1.68 & 1.93 & 1.87 \\
\hline Portugal & 3.01 & 3.08 & 2.76 & 2.52 & 2.19 & 1.74 & 1.43 & 1.45 \\
\hline Spain & 2.86 & 2.94 & 2.84 & 2.79 & 2.22 & 1.63 & 1.33 & 1.19 \\
\hline UK & 2.69 & 2.86 & 2.44 & 1.81 & 1.89 & 1.80 & 1.83 & 1.71 \\
\hline \multicolumn{9}{|c|}{ Females' labour forceparticipation rates (c) } \\
\hline Finland & 57.70 & 59.20 & 61.88 & 64.67 & 68.31 & 70.32 & 73.92 & 73.48 \\
\hline Italy & 31.99 & 32.77 & 33.94 & 38.00 & 40.21 & 41.65 & 45.75 & 47.97 \\
\hline Norway & 28.13 & 32.94 & 38.57 & 49.61 & 62.44 & 66.05 & 70.90 & 73.96 \\
\hline Portugal & 21.50 & 25.70 & 30.07 & 41.62 & 55.01 & 58.77 & 61.45 & 64.81 \\
\hline Spain & 22.51 & 24.95 & 29.15 & 31.42 & 33.05 & 37.63 & 42.56 & 45.31 \\
\hline UK & 44.65 & 47.76 & 51.90 & 55.81 & 58.40 & 60.79 & 65.11 & 66.77 \\
\hline
\end{tabular}

Note (a) Source: Barro and Lee (2001); (b) Total Fertility Rates are the number of births per woman at fecund ages (source World Bank 2000); (c) Females' participation rates are computed by dividing female labour force by the female population aged between 15 and 64 (source World Bank 2000). 
Table 2. Results of the previous literature on female labour force participation and fertility behaviour in Italy

\begin{tabular}{|c|c|c|c|c|c|c|}
\hline \multirow[b]{2}{*}{ Characteistics } & \multicolumn{6}{|c|}{ Artides } \\
\hline & \multicolumn{2}{|c|}{$\begin{array}{l}\text { Colombino and } \\
\text { Di Tommaso (1996) }\end{array}$} & \multicolumn{2}{|c|}{ Del Boca (1999) } & \multicolumn{2}{|c|}{ Di Tommaso (1999) } \\
\hline data set & \multicolumn{2}{|c|}{ SHIW } & \multicolumn{2}{|l|}{ SHIW } & \multicolumn{2}{|l|}{ SHIW } \\
\hline sample composition & \multirow{3}{*}{\multicolumn{2}{|c|}{$\begin{array}{l}\text { women 18-40 } \\
\text { 1987, 1989, } 1991 \\
\text { employment }\end{array}$}} & \multirow{3}{*}{\multicolumn{2}{|c|}{$\begin{array}{l}\text { women 21-45 } \\
\text { 1991, 1993, } 1995 \\
\text { employment }\end{array}$}} & \multirow{3}{*}{\multicolumn{2}{|c|}{$\begin{array}{l}\text { women 18-40 } \\
\text { 1987, 1989, } 1991 \\
\text { employment }\end{array}$}} \\
\hline years & & & & & & \\
\hline $\begin{array}{l}\text { participation } \\
\text { definition }\end{array}$ & & & & & & \\
\hline fertility definition & \multicolumn{2}{|c|}{$\begin{array}{l}\text { one or more children } \\
\text { in the household }\end{array}$} & \multirow{2}{*}{\multicolumn{2}{|c|}{$\begin{array}{l}\text { one or more children } \\
\text { in the household }<2 \\
\text { years old } \\
\text { - fixed effects logit } \\
\text { model ( panel) } \\
\text { - two separate logit } \\
\text { (cross sections) }\end{array}$}} & \multirow{2}{*}{\multicolumn{2}{|c|}{$\begin{array}{l}\text { one or more children } \\
\text { in the household }<18 \\
\text { years old } \\
\text { bivariate probit }\end{array}$}} \\
\hline $\begin{array}{l}\text { econometric } \\
\text { technique }\end{array}$ & \multicolumn{2}{|c|}{ bivariate probit } & & & & \\
\hline \multirow[b]{2}{*}{ Vaniables } & \multicolumn{6}{|c|}{ Effect } \\
\hline & Part. & Fert. & Part. (a) & Fert. (a) & Part. & Fert. \\
\hline woman's wage & + & - & & & $t$ & - \\
\hline husband's wage & - & + & & & - & + \\
\hline unearned income & - & no & & & + & - \\
\hline wealth & no & + & & & - & + \\
\hline centre & - & no & & & & \\
\hline south & - & + & & & & \\
\hline family transfers & & & & + & & \\
\hline child care & & & + & no & & \\
\hline parents alive & & & + & + & & \\
\hline part-time & & & no & + & & \\
\hline schooling & + & - & + & no & & \\
\hline
\end{tabular}

Note The + and - signs show the direction of the effect of the variables listed on participation (Part.) and fertility (Fert.), 'no' means that the effect is not found significant. (a) results for the 1993 cross-section.

Table 3. O bserved distribution of the MNL outcomes by level of women's education

\begin{tabular}{lrrrr}
\hline Education & $(\mathrm{NP}, \mathrm{NF})$ & $(\mathrm{P}, \mathrm{NF})$ & $(\mathrm{NP}, \mathrm{F})$ & $(\mathrm{P}, \mathrm{F})$ \\
\hline Primary & 74.04 & 19.23 & 6.25 & 0.48 \\
Low secondary & 56.90 & 33.16 & 6.90 & 3.03 \\
High secondary & 28.96 & 59.30 & 4.89 & 6.85 \\
Tertiary & 5.61 & 80.37 & 0.00 (a) & 14.02 \\
\hline
\end{tabular}

Note The sample includes 1420 observations. The four LFP and fertility outcomes are: (NP,NF), non participation-non fertility; $(\mathrm{P}, \mathrm{NF})$, participation- non fertility; (NP,F), non participation-fertility; $(\mathrm{P}, \mathrm{F})$ : participation-fertility. (a) The fact that this cell is empty is not a problem since we do not consider dummies for education but a continuous variable, namely the years of education. 
Table 4. Significance of education in the explanation of LFP and fertility

\begin{tabular}{|c|c|c|c|c|c|c|}
\hline & \multicolumn{2}{|c|}{$(\mathrm{P}, \mathrm{NF})$} & \multicolumn{2}{|c|}{$(\mathrm{NP}, \mathrm{F})$} & \multicolumn{2}{|c|}{$(\mathrm{P}, \mathrm{F})$} \\
\hline Variable & \multicolumn{6}{|c|}{ Coeff. t-student Coeff. t-student Coeff. t-student } \\
\hline \multicolumn{7}{|c|}{ MODEL WITH CONTROLS FOR TASTE HETEROGENEITY } \\
\hline Education * (2) & 0.16 & 2.13 & 0.12 & 1.18 & 0.24 & 1.74 \\
\hline Education * (25-29) & 0.19 & 4.02 & 0.11 & 1.34 & 0.36 & 4.30 \\
\hline Education $*(30-3$ & 0.22 & 5.16 & 0.10 & 1.41 & 0.30 & 3.99 \\
\hline Education * ( & 0.29 & 7.41 & 0.01 & 0.11 & 0.34 & 4.63 \\
\hline Prob $>\chi^{2}$ & \multicolumn{6}{|c|}{0.00 (a) } \\
\hline Pseudo $\mathrm{R}^{2}$ & \multicolumn{6}{|c|}{$26.80 \%$} \\
\hline
\end{tabular}

PARSIMONIOUS MODEL

\begin{tabular}{lllllll} 
Education * (21-24) & 0.16 & 2.12 & 0.13 & 1.34 & 0.20 & 1.51 \\
Education * (25-29) & 0.18 & 3.95 & 0.09 & 1.23 & 0.36 & 4.32 \\
Education * (30-34) & 0.21 & 5.19 & 0.09 & 1.38 & 0.30 & 4.02 \\
Education * (35-39) & 0.29 & 7.55 & 0.00 & 0.02 & 0.34 & 4.75 \\
\hline Prob > $\chi^{2}$ & \multicolumn{5}{c}{$0.00^{(\mathrm{a})}$} \\
Pseudo $\mathrm{R}^{2}$ & \multicolumn{7}{c}{$25.69 \%$} \\
\hline
\end{tabular}

\section{NON LINEAR INSTRUMENTAL VARIABLES (NLIV) MODEL(b)}

\begin{tabular}{lllllll} 
Education * (21-24) & 0.13 & 0.58 & -0.20 & -0.37 & 0.16 & 0.16 \\
Education * (25-29) & 0.15 & 0.69 & -0.23 & -0.45 & 0.34 & 0.76 \\
Education * (30-34) & 0.18 & 0.83 & -0.23 & -0.45 & 0.27 & 0.61 \\
Education * (35-39) & 0.26 & 1.20 & -0.33 & -0.61 & 0.32 & 0.71 \\
\hline Prob > $\chi^{2}$ & \multicolumn{7}{c}{0.00 (a) } \\
Pseudo R ${ }^{2}$ & \multicolumn{7}{c}{$23.08 \%$} \\
\hline
\end{tabular}

Note The four LFP and fertility outcomes are: (NP,NF), non participation-non fertility; (P,NF), participation- non fertility; (NP,F), non participation-fertility; $(\mathrm{P}, \mathrm{F})$ : participation-fertility. $(\mathrm{NP}, \mathrm{NF})$ is the reference outcome. The sample includes in all cases 1420 women. (a) test for the joint significance of the whole set of regressors included (except the constant); (b) t-values computed using boostrap (100 replications). 
Table 5. Probabilities (\%) of the MNL outcomes, by level of education and age-group (parsimonious MNL model)

\begin{tabular}{|c|c|c|c|c|c|c|c|}
\hline \multirow[b]{2}{*}{ Education } & \multirow[b]{2}{*}{ Age } & \multicolumn{6}{|c|}{ LFP and fertility outcomes } \\
\hline & & $(\mathrm{NP}, \mathrm{NF})$ & $(\mathrm{P}, \mathrm{NF})$ & $(\mathrm{NP}, \mathrm{F})$ & $(\mathrm{P}, \mathrm{F})$ & $\mathrm{P}^{(\mathrm{a})}$ & $\mathrm{F}^{(\mathrm{b})}$ \\
\hline \multicolumn{8}{|c|}{$\overline{\text { Primary (5 years) }}$} \\
\hline & $21-24$ & 78.2 & 17.0 & 4.5 & 0.3 & 17.3 & 4.8 \\
\hline & $25-29$ & 76.7 & 18.9 & 3.7 & 0.6 & 19.5 & 4.3 \\
\hline & $30-34$ & 74.8 & 21.2 & 3.6 & 0.4 & 21.7 & 4.0 \\
\hline & $35-39$ & 69.0 & 28.4 & 2.1 & 0.5 & 28.9 & 2.6 \\
\hline & & & \multicolumn{4}{|c|}{ "Total fertility" = } & 15.7 \\
\hline \multicolumn{8}{|c|}{ Low secondary (8 years) } \\
\hline & $21-24$ & 69.5 & 24.3 & 5.8 & 0.5 & 24.7 & 6.2 \\
\hline & $25-29$ & 66.0 & 28.2 & 4.3 & 1.5 & 29.7 & 5.7 \\
\hline & $30-34$ & 62.0 & 33.2 & 3.9 & 0.9 & 34.1 & 4.8 \\
\hline & $35-39$ & 49.5 & 48.0 & 1.5 & 1.0 & 49.0 & 2.5 \\
\hline & & & \multicolumn{4}{|c|}{ "Total fertility" = } & 19.3 \\
\hline \multicolumn{8}{|c|}{ High secondary (13 years) } \\
\hline & $21-24$ & 51.5 & 39.6 & 8.0 & 1.0 & 40.5 & 9.0 \\
\hline & $25-29$ & 43.4 & 46.4 & 4.5 & 5.8 & 52.1 & 10.2 \\
\hline & $30-34$ & 37.0 & 56.9 & 3.7 & 2.4 & 59.3 & 6.1 \\
\hline & $35-39$ & 19.3 & 78.0 & 0.6 & 2.2 & 80.2 & 2.8 \\
\hline & & & \multicolumn{4}{|c|}{ "Total fertility"= } & 28.1 \\
\hline \multicolumn{8}{|c|}{$\overline{\text { Tertiary (17 years) }}$} \\
\hline & $21-24$ & - & - & - & - & - & - \\
\hline & $25-29$ & 25.5 & 56.7 & 3.8 & 14.0 & 70.7 & 17.8 \\
\hline & $30-34$ & 20.3 & 72.6 & 2.9 & 4.3 & 76.8 & 7.2 \\
\hline & $35-39$ & 7.1 & 89.6 & 2.2 & 3.2 & 92.7 & 5.4 \\
\hline & \multicolumn{6}{|c|}{ "Total fertility"= } & 30.4 \\
\hline
\end{tabular}

Note The four LFP and fertility outcomes are: (NP,NF), non participation-non fertility; (P,NF), participation- non fertility; (NP,F), non participation-fertility; $(\mathrm{P}, \mathrm{F})$ : participation-fertility. The probabilities of the four MNL outcomes are computed at the sample average values for all variables but education. "Total fertility" is the sum across age groups of the probability of giving birth by educational level. (a) Probability of participation: $\operatorname{Pr}(\mathrm{P}, \mathrm{NF})+\operatorname{Pr}(\mathrm{P}, \mathrm{F})$; (b) Probability of fertility (i.e. of giving birth): $\operatorname{Pr}(\mathrm{NP}, \mathrm{F})+\operatorname{Pr}(\mathrm{P}, \mathrm{F})$. 


\section{APPEN DIX A. Variables description}

The explanatory variables included in the econometric model are:

1. Broad area of residence. This variable is included to account for regional effects due to differences in the institutional and cultural setting. We consider three broad regions: North, Centre, and South.

2. Municipality size. We include the number of inhabitants of the municipality in which a woman resides to capture differences in labour market opportunities and child care availability that may exist between municipalities of different size. We consider four possible dimensions: very small ( $<20$ thousands), small (20-40 thousands), medium (40-500 thousands), big ( $>500$ thousands).

3. Partner's income. We include the net disposable total husband's income (in thousands of Italian lira) to control for pure income effects.

4. Parents' availability. This variable is a dummy for 'parents' availability' and is included as a proxy for the availability of low cost external child care. We build the variable as follows. For each spouse we check if the province of birth is equal to that of residence, in which case we check if his/ her mother was still alive. If both conditions are satisfied for at least one of the spouses, parents are considered 'available' (we assume that parents did not change the province of residence since the birth of their child, and that they resided in the province in which birth took place). We consider only the mother to account for a possible gender role model (especially for older people). We prefer this variable, which may nevertheless have some pitfalls, to that of parents living in the household, used in other works (see for example Barrow 1999 or D el Boca et al. 2000) since we consider the interpretation of the effect of the latter more problematic. In fact, living with one's own parents is probably non-random. A mechanism of non-random selection might be at work, for example parents could be in bad health conditions (for which we can not control) and the effect on LFP and fertility may be just in the opposite direction to that expected. Anyway, our measure nests that used by previous studies even if the effect of self-selection should be less harmful.

5. 'Easterlin variables'. The 1993 wave of SHIW contains a section on intergenerational information. In particular there is a question on the relative position of the family in terms of accumulated wealth compared to the husband's and wife's families. There are three possibilities: less, equal or more resources.

6. Parents' education. We consider the educational qualifications of a woman's parents. In particular for the father we consider six educational categories: 1) missing education; 2) no formal education; 3) elementary; 4) low secondary; 5) high secondary; 6) degree. For the mother the last two categories are grouped, since the low number of mothers with a university education caused several problems to the estimation procedure.

7. Father's job qualification. We consider the following qualifications: 1) not known; 2) blue collar, white collar low (low skilled) or unemployed; ${ }^{38} 3$ ) teacher or white collar high (medium skilled); 4) manager, head master, university teacher, professional, entrepreneur (high skilled); 5) self-employed;

8. Father's branch of activity. We consider the following branches: 1) not known or not applicable; 2) agriculture, hunting, fishing; 3) manufacturing; 4) public administration; 5) other.

\footnotetext{
${ }^{38}$ We can not consider the unemployed category separately since the cell of the outcome $(\mathrm{P}, \mathrm{F})$ is empty.
} 
9. Mother's job qualification. We consider the following categories: 1) not known; 2) blue collar and white collar low (low skilled); 3 ) teacher, white collar high, manager, head master, university teacher, professional, entrepreneur (medium and high skilled); 4) self-employed; 5) not working. Compared to father's education categories 3 and 4 are grouped since only three mothers fall in category 4 .

10. Mother's branch of activity. See the father's branch of activity.

11. Husband's education. We include four dummies: 1) primary schooling; 2) lowsecondary schooling; 3) high-secondary schooling; 4) university degree or more.

12. Husband's job qualifications. We include 5 dummies: 1) low skilled; 2) medium skilled; 3) high skilled; 4) self-employed; 5) unemployed; 39

13. Husband's branch of activity. We include five dummies: 1) agriculture, hunting, fishing; 2) building; 3) manufacturing; 4) public administration; 5) other.

14. Husband's age.

15. Child care availability. We use data on child care availability, namely places available in public institutions providing child care by province (ISTAT 1995), and data on population aged less than two by province, from the 1991 Census data (ISTAT 1993), in order to build a ratio giving a measure of the 'degree of coverage' of the local potential demand for public child care.

${ }^{39}$ For the content of the different categories see father's job qualifications. 


\section{APPEN DIX B. FURTHER TABLES}

Table B1. MNL with controls for heterogeneity

\begin{tabular}{|c|c|c|c|c|c|c|}
\hline \multirow[t]{2}{*}{$\overline{\text { Variable }}$} & \multicolumn{2}{|c|}{$(\mathrm{P}, \mathrm{NF})$} & \multicolumn{2}{|c|}{$(\mathrm{NP}, \mathrm{F})$} & \multicolumn{2}{|c|}{$(\mathrm{P}, \mathrm{F})$} \\
\hline & Coeff. & t-student & Coeff. & t-student & Coeff. & t-student \\
\hline$\overline{\text { Husband's income }}$ & $-1.4 \mathrm{E}-05$ & -2.195 & $81 \mathrm{E}-06$ & 0.63 & $3.1 \mathrm{E}-05$ & -2.62 \\
\hline Education*(21-24) & 0.16 & 2.13 & 0.12 & 1.18 & 0.24 & 1.74 \\
\hline Education* (25-29) & 0.19 & 4.02 & 0.11 & 1.34 & 0.36 & 4.30 \\
\hline Education* $(30-34)$ & 0.22 & 5.16 & 0.10 & 1.41 & 0.30 & 3.99 \\
\hline Education* (35-39) & 0.29 & 7.41 & 0.01 & 0.11 & 0.34 & 4.63 \\
\hline Parents available & 0.90 & 3.53 & 0.92 & 1.87 & -0.01 & -0.03 \\
\hline Public childcare & 11.51 & 3.85 & -8.32 & -1.55 & 1.18 & 0.23 \\
\hline Father's education: none & -0.27 & -0.73 & 0.12 & 0.26 & -0.16 & -0.22 \\
\hline Father's education: low secondary & -0.57 & -1.91 & -0.42 & -0.87 & -0.30 & -0.54 \\
\hline Father's education: high secondary & 0.29 & 0.63 & 1.28 & 1.47 & -0.76 & -1.20 \\
\hline Father's education: degree & -0.38 & -0.49 & 0.06 & 0.03 & 0.31 & 0.27 \\
\hline Mother's education: none & -0.12 & -0.37 & -0.03 & -0.07 & -1.98 & -2.32 \\
\hline Mother's education: low secondary & 0.29 & 0.80 & -1.96 & -2.58 & 0.48 & 0.76 \\
\hline Mother's education: high secondary or higher & -0.64 & -1.09 & -0.79 & -0.66 & -0.18 & -0.25 \\
\hline Father's job: missing & -1.61 & -2.15 & -1.13 & -1.64 & -2.30 & -2.12 \\
\hline Father's job: medium skilled & 0.73 & 1.14 & -1.93 & -1.17 & 1.39 & 1.63 \\
\hline Father's job: high skilled & 0.11 & 0.21 & -0.79 & -0.63 & 0.12 & 0.15 \\
\hline Father's job: self-employed & -0.18 & -0.65 & 0.00 & -0.01 & -0.40 & -0.83 \\
\hline Father's branc & -0.55 & -1.27 & 0.49 & 0.67 & -0.77 & -1.13 \\
\hline Father's branch: agriculture & 0.03 & 0.10 & 0.40 & 0.94 & 0.85 & 1.43 \\
\hline Father's branch: manufacture & -0.25 & -0.90 & -0.50 & -0.89 & 0.11 & 0.23 \\
\hline Father's branch: PA & -0.45 & -1.51 & -0.84 & -1.50 & -0.58 & -1.31 \\
\hline Mother's job: missing & 1.37 & 1.58 & 1.98 & 2.34 & 1.33 & 1.08 \\
\hline Mother's job: low skilled & 0.50 & 0.93 & -0.36 & -0.35 & -3.29 & -2.27 \\
\hline Mother's job: medium and hig & 0.54 & 0.77 & -0.47 & -0.26 & -1.96 & -1.53 \\
\hline Mother's job: self-employed & -0.82 & -1.36 & -1.22 & -1.00 & -0.42 & -0.23 \\
\hline Mother's branch: low skilled & 0.20 & 0.32 & 1.56 & 1.44 & -0.55 & -0.24 \\
\hline Mother's branch: agriculture & 0.64 & 0.99 & 0.22 & 0.17 & 2.37 & 1.54 \\
\hline Mother's branch: PA & 1.18 & 1.75 & -0.89 & -0.59 & 3.89 & 3.04 \\
\hline Mother's branch: other & 0.63 & 1.13 & 1.07 & 0.98 & 1.09 & 0.66 \\
\hline Husband's education: primary & 0.00 & -0.01 & -0.23 & -0.44 & -2.24 & -1.79 \\
\hline Husband's education: high secondary & 0.38 & 1.64 & -0.27 & -0.60 & 0.11 & 0.23 \\
\hline Husband's education: degree & 1.04 & 2.08 & -0.52 & -0.38 & 0.80 & 1.06 \\
\hline Husband's job: medium skilled & -0.26 & -0.57 & -1.42 & -1.58 & 0.00 & 0.01 \\
\hline Husband's job: high skilled & -0.56 & -2.09 & 0.10 & 0.25 & -0.26 & -0.38 \\
\hline Husband's job: self-employed & -0.80 & -1.75 & -0.45 & -0.51 & -0.36 & -0.54 \\
\hline Husband unemployed & 0.26 & 0.46 & 0.67 & 0.97 & -1.32 & -1.14 \\
\hline Husband's branch: agriculture & 0.16 & 0.30 & 0.56 & 0.83 & -0.51 & -0.36 \\
\hline Husband's branch: building & -0.25 & -0.91 & -0.22 & -0.46 & 0.23 & 0.40 \\
\hline Husband's branch: manufacturing & -0.10 & -0.31 & -0.77 & -1.50 & 1.02 & 1.57 \\
\hline Husband's branch: other & 0.03 & 0.12 & 0.04 & 0.08 & -0.30 & -0.55 \\
\hline Husband's age & -0.06 & -2.18 & -0.11 & -2.32 & -0.07 & -1.37 \\
\hline Mother in law worked & 0.53 & 2.36 & -1.06 & -1.86 & 0.64 & 1.50 \\
\hline constant & -1.79 & -1.45 & 0.27 & 0.14 & -2.95 & -1.62 \\
\hline N. obs. & & & 142 & & & \\
\hline Overall p-value & & & 0.00 & & & \\
\hline Pseudo $\mathrm{R}^{2}$ & & & 26.8 & & & \\
\hline
\end{tabular}

Note $(\mathrm{NP}, \mathrm{NF})$ is the reference outcome. The model controls also for the area of residence, the municipality size and Easterlin's variables (see Appendix A). The reference characteristics are: southern residence; medium municipality; father's education: primary school; father's job: low skilled or unemployed; father's branch: other; mother's education: primary school; mother's job: not working; mother's branch: not applicable; 'parents not available'; mother in law did not work; husband's education: low secondary; husband's job: low skilled; husband's branch: other. (a) test for the joint significance of the whole set of the regressors included (except the constant). 
Table B2. Hausman test of the independence of irrelevant alternatives

\begin{tabular}{lcc}
\hline \multicolumn{1}{c}{ O mitted outcome } & Test statistic & p-value \\
\hline & & \\
$(\mathrm{NP}, \mathrm{NF})$ & -23.95 & (a) \\
$(\mathrm{P}, \mathrm{NF})$ & 12.97 & 1.00 \\
$(\mathrm{NP}, \mathrm{F})$ & -0.79 & (a) \\
$(\mathrm{P}, \mathrm{F})$ & -3.75 & (a) \\
& & \\
\hline
\end{tabular}

Note In all cases the Hausman test shows that the IIA assumptions can not be rejected. (a) Hausman and McFadden (1984, footnote 4) maintains that the fact that the test statistic takes on a negative value can be interpreted as a strong evidence against rejecting the hypothesis that the IIA assumption holds. 
Table B3. Parsimonious MNL model

\begin{tabular}{|c|c|c|c|c|c|c|}
\hline \multirow[t]{2}{*}{$\overline{\text { Variable }}$} & \multicolumn{2}{|c|}{$\overline{(\mathrm{P}, \mathrm{NF})}$} & \multicolumn{2}{|c|}{$\overline{(\mathrm{NP}, \mathrm{F})}$} & \multicolumn{2}{|c|}{$\overline{(\mathrm{P}, \mathrm{F})}$} \\
\hline & $\overline{\text { Coeff. }}$ & t-student & Coeff. & t-student & Coeff. & t-student \\
\hline Husband's income & $-1.3 \mathrm{E}-05$ & -2.09 & $7.92 \mathrm{E}-06$ & $\overline{0.84}$ & $-3 \mathrm{E}-05$ & -2.48 \\
\hline Education * (21-24) & 0.16 & 2.12 & 0.13 & 1.34 & 0.20 & 1.51 \\
\hline Education * (25-29) & 0.18 & 3.95 & 0.09 & 1.23 & 0.36 & 4.32 \\
\hline Education * (30-34) & 0.21 & 5.19 & 0.09 & 1.38 & 0.30 & 4.02 \\
\hline Education * (35-39) & 0.29 & 7.55 & 0.00 & 0.02 & 0.34 & 4.75 \\
\hline Parents available & 0.89 & 3.54 & 0.87 & 1.78 & 0.07 & 0.15 \\
\hline Public childcare & 11.40 & 3.92 & -7.38 & -1.37 & 0.93 & 0.18 \\
\hline Father's education: none & -0.24 & -0.66 & 0.17 & 0.39 & 0.03 & 0.04 \\
\hline Father's education: low secondary & -0.59 & -2.03 & -0.59 & -1.24 & -0.34 & -0.62 \\
\hline Father's education: high secondary & 0.34 & 0.76 & 0.98 & 1.08 & -0.64 & -1.02 \\
\hline Father's education: degree & -0.23 & -0.30 & -0.89 & -0.48 & 0.43 & 0.42 \\
\hline Mother's education: none & -0.13 & -0.40 & 0.05 & 0.12 & -2.00 & -2.24 \\
\hline Mother's education: low secondary & 0.25 & 0.69 & -1.76 & -2.44 & 0.48 & 0.77 \\
\hline Mother's education: high secondary or higher & -0.57 & -0.92 & -0.59 & -0.51 & 0.03 & 0.04 \\
\hline Mother's job: missing & 0.62 & 0.67 & 1.71 & 1.93 & 0.46 & 0.26 \\
\hline Mother's job: low skilled & 0.47 & 0.92 & -0.09 & -0.09 & -3.35 & -2.24 \\
\hline Mother's job: medium and high skilled & 0.51 & 0.77 & -0.22 & -0.16 & -2.09 & -1.62 \\
\hline Mother's job: self-employed & -0.91 & -1.57 & -0.80 & -0.70 & -0.81 & -0.49 \\
\hline Mother's branch: low skilled & 0.34 & 0.59 & 1.42 & 1.40 & 0.08 & 0.04 \\
\hline Mother's branch: agriculture & 0.68 & 1.13 & -0.30 & -0.23 & 2.66 & 1.74 \\
\hline Mother's branch: PA & 1.11 & 1.70 & -1.42 & -0.99 & 3.72 & 2.89 \\
\hline Mother's branch: other & 0.72 & 1.33 & 0.80 & 0.77 & 1.23 & 0.84 \\
\hline Husband's education: primary & -0.03 & -0.12 & -0.20 & -0.41 & -2.12 & -1.69 \\
\hline Husband's education: high secondary & 0.36 & 1.55 & -0.30 & -0.68 & 0.07 & 0.15 \\
\hline Husband's education: degree & 1.06 & 1.98 & -0.64 & -0.46 & 0.86 & 1.09 \\
\hline Husband's job: medium skilled & -0.15 & -0.32 & -1.31 & -1.44 & 0.04 & 0.06 \\
\hline Husband's job: high skilled & -0.55 & -2.11 & 0.11 & 0.27 & -0.25 & -0.36 \\
\hline Husband's job: self-employed & -0.78 & -1.74 & -0.40 & -0.47 & -0.14 & -0.20 \\
\hline Husband unemployed & 0.22 & 0.39 & 0.70 & 1.04 & -1.35 & -1.13 \\
\hline Husband's branch: agriculture & 0.19 & 0.36 & 0.67 & 0.98 & -0.44 & -0.34 \\
\hline Husband's branch: building & -0.32 & -1.21 & -0.22 & -0.51 & 0.23 & 0.40 \\
\hline Husband's branch: manufacturing & -0.11 & -0.36 & -0.89 & -1.74 & 1.03 & 1.59 \\
\hline Husband's branch: other & -0.01 & -0.05 & -0.07 & -0.14 & -0.39 & -0.74 \\
\hline Husband's age & -0.06 & -2.20 & -0.10 & -2.18 & -0.06 & -1.29 \\
\hline Mother in law worked & 0.54 & 2.40 & -1.02 & -1.82 & 0.65 & 1.56 \\
\hline constant & -1.92 & -1.56 & -0.06 & -0.03 & -3.28 & -1.78 \\
\hline N.obs. & & & 142 & & & \\
\hline Overall $p$-value & & & 0.00 & & & \\
\hline Pseudo $\mathrm{R}^{2}$ & & & 25.69 & & & \\
\hline
\end{tabular}

Note $(\mathrm{NP}, \mathrm{NF})$ is the reference outcome. The model controls also for area of residence, the municipality size and Easterlin's variables (see Appendix A). The reference characteristics are: southern residence; medium municipality; father's education: primary school; mother's education: primary school; mother's job: not working; mother's branch: not applicable; 'parents not available'; mother in law did not work; husband's education: low secondary; husband's job: low skilled; husband's branch: other. (a) test for the joint significance of the whole set of the regressors included (except the constant). 
Table B4. Education equation

\begin{tabular}{lrrr}
\hline Variable & Coeff. & t-student & p-value \\
\hline North & -0.32 & -1.09 & 0.27 \\
Centre & -0.27 & -0.94 & 0.35 \\
Town: very small & 0.05 & 0.25 & 0.80 \\
Town: small & -0.26 & -1.08 & 0.28 \\
Town: big & -0.22 & -0.85 & 0.39 \\
Father's education: none & -0.48 & -1.51 & 0.13 \\
Father's education: low secondary & 0.33 & 1.18 & 0.24 \\
Father's education: high secondary & 1.12 & 2.83 & 0.01 \\
Father's education: degree & 2.31 & 3.61 & 0.00 \\
Father's job: missing & 0.40 & 0.38 & 0.70 \\
Father's job: medium skilled & 1.36 & 2.57 & 0.01 \\
Father's job: high skilled & 1.44 & 2.95 & 0.00 \\
Father's job: self-employed & 1.16 & 4.44 & 0.00 \\
Father's branch: missing & 0.01 & 0.02 & 0.99 \\
Father's branch: agriculture & -0.19 & -0.62 & 0.53 \\
Father's branch: manufacture & 0.52 & 1.99 & 0.05 \\
Father's branch: public administration & 0.61 & 2.05 & 0.04 \\
Mother's education: none & -0.56 & -1.82 & 0.07 \\
Mother's education: low secondary & 0.34 & 1.05 & 0.30 \\
Mother's education: high secondary or higher & -0.19 & -0.46 & 0.65 \\
Mother's job: missing & -0.53 & -0.47 & 0.64 \\
Mother's job: low skilled & 0.30 & 0.62 & 0.54 \\
Mother's job: medium and high skilled & 0.23 & 0.35 & 0.72 \\
Mother's job: self-employed & 0.54 & 1.02 & 0.31 \\
Mother's branch: low skilled & -0.77 & -1.38 & 0.17 \\
Mother's branch: agriculture & -0.72 & -0.94 & 0.35 \\
Mother's branch: PA & 0.86 & 1.56 & 0.12 \\
Mother's branch: other & 0.59 & 1.16 & 0.25 \\
constant & 9.37 & 13.06 & 0.00 \\
\hline N.obs. & \multicolumn{3}{c}{1420} \\
Overall p-value & 0.00 (a) & \\
$\mathrm{R}^{2}$ & $49.08 \%$ & \\
\hline
\end{tabular}

Note The dependent variable is the number of years of formal education. The reference characteristics are: southern residence; medium municipality; father's education: primary school; father's job: low skilled or unemployed; father's branch: other; mother's education: primary school; mother's job: not working; mother's branch: not applicable. The regressions included also all the other explanatory variables included in table B1. (a) test for the joint significance of the whole set of the regressors included (except the constant). 
Table B5. Non Liner Instrumental Variables (NLIV) MNL model

\begin{tabular}{|c|c|c|c|c|c|c|}
\hline \multirow[t]{2}{*}{$\overline{\text { Variable }}$} & \multicolumn{2}{|c|}{$(\mathrm{P}, \mathrm{NF})$} & \multicolumn{2}{|c|}{$(\mathrm{NP}, \mathrm{F})$} & \multicolumn{2}{|c|}{$(\mathrm{P}, \mathrm{F})$} \\
\hline & Coeff. & t-student & Coeff. & t-student & Coeff. & t-student \\
\hline Husband's income & $-1.3 \mathrm{E}-05$ & -2.04 & $9.8 \mathrm{E}-06$ & 0.96 & $-2.7 \mathrm{E}-05$ & -2.41 \\
\hline Education* (21-24) & 0.13 & 0.58 & -0.20 & -0.37 & 0.16 & 0.16 \\
\hline Education* (25-29) & 0.15 & 0.69 & -0.23 & -0.45 & 0.34 & 0.76 \\
\hline Education* (30-34) & 0.18 & 0.83 & -0.23 & -0.45 & 0.27 & 0.61 \\
\hline Education* (35-39) & 0.26 & 1.20 & -0.33 & -0.61 & 0.32 & 0.71 \\
\hline Parents available & 0.83 & 3.40 & 0.87 & 1.74 & 0.04 & 0.07 \\
\hline Public childcare & 11.26 & 3.79 & -5.84 & -0.88 & 0.60 & 0.12 \\
\hline Father's education: none & -0.30 & -0.83 & -0.03 & -0.06 & 0.06 & 0.08 \\
\hline Father's education: low secondary & -0.54 & -1.88 & -0.42 & -0.84 & -0.20 & -0.37 \\
\hline Father's education: high secondary & 0.44 & 0.91 & 1.40 & 1.28 & -0.63 & -0.88 \\
\hline Father's education: degree & -0.11 & -0.12 & 0.07 & 0.03 & 0.67 & 0.45 \\
\hline Mother's education: none & -0.09 & -0.27 & -0.10 & -0.20 & -2.03 & -2.30 \\
\hline Mother's education: low secondary & 0.25 & 0.69 & -1.71 & -2.39 & 0.39 & 0.65 \\
\hline Mother's education: high secondary or higher & -0.59 & -0.98 & -0.69 & -0.58 & -0.10 & -0.15 \\
\hline Mother's job: missing & 0.44 & 0.60 & 1.42 & 1.52 & 0.27 & 0.16 \\
\hline Mother's job: low skilled & 0.34 & 0.69 & 0.00 & 0.00 & -3.35 & -2.30 \\
\hline Mother's job: medium and high skilled & 0.52 & 0.80 & -0.08 & -0.06 & -2.11 & -1.66 \\
\hline Mother's job: self-employed & -0.96 & -1.64 & -0.41 & -0.34 & -0.82 & -0.49 \\
\hline Mother's branch: low skilled & 0.41 & 0.73 & 1.06 & 1.01 & 0.17 & 0.08 \\
\hline Mother's branch: agriculture & 0.83 & 1.34 & -0.56 & -0.42 & 2.79 & 1.79 \\
\hline Mother's branch: PA & 1.15 & 1.69 & -1.21 & -0.81 & 3.71 & 2.93 \\
\hline Mother's branch: other & 0.79 & 1.44 & 0.91 & 0.82 & 1.25 & 0.86 \\
\hline Husband's education: primary & -0.02 & -0.07 & -0.49 & -0.86 & -2.09 & -1.73 \\
\hline Husband's education: high secondary & 0.39 & 0.89 & 0.32 & 0.34 & 0.05 & 0.07 \\
\hline Husband's education: degree & 1.06 & 1.24 & 0.49 & 0.24 & 0.78 & 0.57 \\
\hline Husband's job: medium skilled & -0.16 & -0.36 & -1.13 & -1.24 & 0.13 & 0.19 \\
\hline Husband'sjob: high skilled & -0.53 & -2.05 & 0.24 & 0.54 & -0.30 & -0.45 \\
\hline Husband's job: self-employed & -0.81 & -1.74 & -0.22 & -0.26 & 0.00 & 0.00 \\
\hline Husband unemployed & 0.15 & 0.26 & 0.39 & 0.50 & -1.50 & -1.27 \\
\hline Husband's branch: agriculture & 0.10 & 0.22 & 0.76 & 1.09 & -0.29 & -0.23 \\
\hline Husband's branch: building & -0.32 & -1.20 & -0.10 & -0.21 & 0.19 & 0.32 \\
\hline Husband's branch: manufacturing & -0.20 & -0.63 & -1.01 & -1.97 & 0.96 & 1.51 \\
\hline Husband's branch: other & -0.01 & -0.02 & 0.05 & 0.10 & -0.46 & -0.85 \\
\hline Husband's age & -0.07 & -2.25 & -0.11 & -2.31 & -0.06 & -1.33 \\
\hline Mother in law worked & 0.52 & 2.51 & -1.00 & -1.85 & 0.56 & 1.41 \\
\hline constant & -1.47 & -0.68 & 3.16 & 0.78 & -3.00 & -0.90 \\
\hline N. obs. & & & 14 & 20 & & \\
\hline Overall p-value & & & 0.0 & $0^{(a)}$ & & \\
\hline Pseudo $\mathrm{R}^{2}$ & & & 23.0 & & & \\
\hline
\end{tabular}

Note $(\mathrm{NP}, \mathrm{NF})$ is the reference outcome. The model controls also for area of residence, the municipality size and Easterlin's variables (see Appendix A). The reference characteristics are: southern residence; medium municipality; father's education: primary school; mother's education: primary school; mother's job: not working; mother's branch: not applicable; 'parents not available'; mother in law did not work; husband's education: low secondary; husband's job: low skilled; husband's branch: other. (a) test for the joint significance of the whole set of the regressors included (except the constant). 
Table B6. Correlation between instruments and MNL residuals (NLIV model)

\begin{tabular}{lrrrr}
\hline Instruments & \multicolumn{4}{c}{ MNL residuals } \\
\cline { 2 - 5 } & \multicolumn{1}{c}{ e1 } & \multicolumn{1}{c}{ e2 } & e3 & \multicolumn{1}{c}{ e4 } \\
\hline Father's job: missing & 0.057 & -0.020 & -0.048 & -0.027 \\
Father's job: medium skilled & 0.003 & 0.041 & -0.020 & -0.071 \\
Father's job: high skilled & -0.015 & 0.021 & 0.017 & -0.031 \\
Father's job: self-employed & -0.034 & 0.014 & 0.048 & -0.008 \\
Father's branch: missing & 0.021 & -0.042 & 0.014 & 0.028 \\
Father's branch: agriculture & -0.014 & -0.008 & -0.001 & 0.048 \\
Father's branch: manufacture & 0.019 & -0.023 & -0.007 & 0.015 \\
Father's branch: public administration & 0.030 & 0.008 & -0.011 & -0.067 \\
\hline
\end{tabular}

Note e1, e2, e3 and e4 are the difference between observed and predicted outcomes from the MNL model. 


\section{References}

Ahn N, Mira P (1999) A Note on the Changing Relationship between Fertility and Female Employment Rates in D eveloped Countries. FEDEA Doamentode Trabajo n. 9909, forthcoming in Jaumal of PopulationEconamic.

Banca d'Italia (1995) I Bilanci delle Famiglie Italiane nell'Anno 1993. Supplementi al Bdlettino Statistica, NoteMetoddogideeInformazioni Statistiche Anno V, n. 9.

Barro RJ, Lee JW (2001) International D ata on Educational Attainment: Updates and Implications. OxfordEconamicPapers 53: 541-563.

Barrow L (1999) Child Care Costs and the Return-to-Work Decisions of New Mothers. EconomicPerspetives4: 42-55.

Becker G S (1981) A Treatiseon theFamily. Harvard University Press, Cambridge, MA.

Becker G S, Lewis HG (1973) On the Interaction between the Quantity and Q uality of Children. Jaumal ofPditical Econamy82: S279-S288.

Ben-Porath Y. (1973) Short-term Fluctuations in Fertility and Economic Activity in Israel. Demogaphy 10: 185-204.

Blackburn ML, Bloom DE, Neumark D (1993) Fertility Timing, Wages and Human Capital. Jaumal of Population Economics 6: 1-30.

Blau D M, Hagy AP (1998) The D emand for Quality in Child Care. Jamal of Pditical Economy106: 104-146.

Bloemen H, Kalwij, AS (2001) Female Labor Market Transitions and the Timing of Births: A Simultaneous Analysis of the Effects of Schooling. Labar Economics 8: 593620.

Blundell R, D earden L, G oodman A, Reed H (1997) Higher Education, Emplgment and EamingsinBritain Institute for Fiscal Studies, London.

Bound J, Jaeger DA, Backer RM (1995) Problems with Instrumental Variables Estimation when the Correlation between the Instruments and the Endogenous Explanatory Variable is Weak. Jaumal of theAmeican Statistical Assoiation90: 443-450.

Browning M. (1992) Children and Household Economic Behavior. Jamal of Econamic Literature30: 1434-1475.

Chiappori P-A (1992) Collective Labor Supply and Welfare. Jaumal of Pditical Economy 100: 437-467.

Chiuri MC (2000) Quality and D emand of Child Care and Female Labour Supply in Italy. Labour 14: 97-118.

Cigno A and Ermisch J (1989) A Microeconomic Analysis of The Timing of Births. European EconomicReiew, 33: 737-760.

Cigno A (1991) Econamis of theFamily. Clarendon Press, Oxford.

Cigno A, Rosati FC (1996) Jointly D etermined Saving and Fertility Behaviour: Theory, and Estimates for G ermany, Italy, UK and USA. European EconamicReiew40: 1561-1589.

CNEL (2000) Econmia ddla Famigia e Pditiche Sociali D ocumenti CNEL, Consiglio Nazionale dell'Economia e del Lavoro, Roma.

Colombino U, Di Tommaso ML (1996) Is the Preference for Children so Low or is the Price of Time so High? A Simultaneous Model of Fertility and Participation in Italy with Cohort Effects. Labarr10: 475-493.

D agenais MG (1999) Inconsistency of a Proposed Nonlinear Instrumental Variables Estimator for Probit and Logit Models with Endogenous Regressors. Economics Lettes63: 19-21.

Dazinger L, Neuman S (1989) Intergenerational Effects on Fertility: Theory and Evidence from Israel. Jaumal of PopulationEconomics 2: 25-37.

D e Tray D N (1973) Child Q uality and the Demand for Children. Jaumal of Pditical Ecomamy82: S70-S95. 
D el Boca D (1997) Intrahousehold Distribution of Resources and Labor Market Participation D ecisions. In: Persson, I. and Jonunug, C. (eds) Econamics of the Family and FamilyPdicies, Routledge, London, 65-83.

D el Boca D (1999) Participation and Fertility Behavior of Italian Women: The Role of Market Rigidities. NYU C.V. Star Center Working Papes, New York, forthcoming in Jaimal of PopulationEconomics.

Del Boca D, Locatelli M, Pasqua S (2000) Employment Decisions of Married Women: Evidence and Explanations. Labour 14: 35-52.

D ex S, Joshi H (1999) Careers and Motherhood: Policies for Compatibility. Canbridge Jaumal of Econamics 23: 641-659.

Di Tommaso ML (1999) A Trivariate Model of Participation, Fertility and Wages: The Italian Case. CambridgeJaumal of Economics 23: 623-640.

Di Tommaso ML, Weeks M (2000) D ecision Structures and Discrete Choices: An Application to Labour Market Participation and Fertility. DAE WorkingPapers n.00-09, University of Cambridge, Cambridge, UK.

Ermisch JF (1989) Purchased Child Care, Optimal Family Size and Mother's Employment: Theory and Economic Analysis. Jaumal ofPopulationEconomics 2: 79-102.

Filippin A (1997) I Bilanci delle Famiglie Italiane in Formato Stata. Lavoroe Rdazioni Industriali 2: 177-85.

Giannelli GC (1997) Squilibrio dell'offerta di lavoro e rigidità dell'orario di lavoro: un'analisi microeconometrica su un campione nazionale e un campione regionale. Pditica Econamica 13: 87-115.

Grogger J (1990) A Simple Test for Exogeneity in Probit, Logit and Poisson Regression Models. Economics Letters33: 329-332.

Gustafsson S (2001) Optimal Age at Motherhood. Theoretical and Empirical Considerations on Postponement of Maternity in Europe. Jaumal of Population Econamis 14: 225-247.

Gustafsson S, Kenjoh E, Wetzels C (2001) The Role of Education in Postponement of Maternity in Britain, Germany, the Netherlands and Sweden. Paper presented at the 15thAmnal Conference of the European Sociey for Population Economics

Hausman J, McFadden D (1984) Specification Tests for the Multinomial Logit Model. Econamatica 52: 1219-1240.

Hotz VJ, Klerman JA, Willis RJ (1997) The Economics of Fertility in Developed Countries. In: Rosenzweig MR, Stark O (eds) Handbook of Population and Family Economics V dume1A, Elsevier, Amsterdam, 275-347.

ISTAT (1993) Censimento Geneale della Popdazionee delle Abitazioni 20 Ottdare 1991. ISTAT, Rome.

ISTAT (1995), Statistiche della Previdenza, della Sanità e dell'Assistenza Sociale, Anni 1992, 1993, Anmarion. 33, ISTAT, Rome.

Lam D, Duryea S (1999) Effects of Schooling on Fertility, Labor Supply, and Investments in Children, with Evidence from Brazil. Jaumal of Human Resarces, 34: 160192.

Leher E, Nerlove M (1986) Female Labor Force Behavior and Fertility in the United States. Amual Rexiewof Soidogy12: 181-204.

Lillard LA, Waite LJ (1993) A Joint Model of Marital Childbearing and Marital Disruption. Demogaphy, 30: 215-229.

Lucchetti R (2000) Inconsistency of Naive GMM Estimation for QR Models with Endogenous Regressors. Quadami di Ricaca n. 140, Dipartimento di Economia, Università degli Studi di Ancona, Ancona. 
Macunovich DJ (1996) A Review of Recent Developments in the Economics of Fertility. In: P. Menchik (ed) Hasddd and Family Economics, Kluwer Academic, Boston, 91-150.

McFadden D (1974) Conditional Logit Analysis of Qualitative Behavior. In: Zarembka P (ed) FrontiesinEconmmtrics, Academic Press, New Y ork, 105-142.

Moffit R (1984) Profiles of Fertility, Labour Supply and Wages of Married Women: A Complete Life-Cycle Model. Reiewof EconomicStudies, 51:263-278.

Mott FL, Shapiro D (1979) Labor Supply Behavior of Prospective and New Mothers.

Demogaphy16: 199-208

Mott FL, Shapiro D (1983) Complementarity of Work and Fertility among Young American Mothers. Population Studies37: 239-252.

Murphy KM, Welch F (1992) The Structure of Wages. Quartely Jamal of Economics 107: 285-326.

Nakamura A, Nakamura N (1992) The Econometrics of Female Labour Supply and Children. EconomericReiens 11: 1-71.

Parkman AM (1992) Unilateral Divorce and the Labor-Force Participation Rate of Married Women, Revisited. Ameican EconomicReiew82: 671-678.

Parkman AM (1998) Why Are Married Women Working So Hard?. Intemational Reiew of LawandEconomics, 18: 41-49.

Rosenzweig TW, Schultz TP (1985) The Demand and Supply of Births. American EconomicReiex 75: 992-1015.

Sander W (1992) The Effect of Women's Schooling on Fertility. Ecomomic Lettes, 40: 229-233.

Schultz TP (1993) Returns to Women's Education. In: King EM, Hill MA (eds) Women's Eduration in Dexdqaing Cantries Bamies, Benfits and Pdicees Johns Hopkins University Press, Baltimore, 51-99.

Schultz TP (1997) Demand for Children in Low Income Countries. In: Rosenzweig MR, Stark $O$ (eds) Handbook of Population and Family Econmics Vdume 1A, Elsevier, Amsterdam, 349-430.

Smith I (1997) Explaining the Growth of Divorce in Great Britain. Scettish Jarmal of Pditical Economy44: 519-543.

Smith RJ (1986) An Exogeneity Test for a Simultaneous Equation Tobit Model with an Application to Labor Supply. Economicica, 54: 679-686.

Weeks M, Orme C (1999) The Statistical Relationship between Bivariate and Multinomial Choice Models. DAE Working Papers n. 99-12, University of Cambridge, Cambridge, UK.

World Bank (2000) Wodd Dexdqpmet Indicatars 1999 on CD-ROM World Bank, Washington D.C. 